Cahiers du MONDE RUSSE

\section{Cahiers du monde russe}

Russie - Empire russe - Union soviétique et États indépendants

$53 / 2-3 \mid 2012$

L'invention de la Sainte Russie

\title{
ВИДЕНИЕ ХРАМА И ГРАДА
}

О ИЕРУСАЛИМСКОЙ СИМВОЛИКЕ СКУЛЬПТУРНЫХ ИКОН НА ФАСАДАХ РУССКИХ ХРАМОВ ХІІ-ХІІІ ВЕКОВ

La vision de la ville et du temple: La symbolique de Jérusalem dans les icônes sculptées sur les façades des églises russes des XII et XIII ${ }^{e}$ siècles

A vision of city and temple: Jerusalem symbolism in sculptural icons on facades of twelfth-century Russian churches

\section{Алексей М. Лидов}

\section{OpenEdition} Journals

\section{Édition électronique}

URL : http://journals.openedition.org/monderusse/9380

DOI : 10.4000/monderusse. 9380

ISSN : $1777-5388$

Éditeur

Éditions de l'EHESS

\section{Édition imprimée}

Date de publication : 15 septembre 2012

Pagination : 301-318

ISSN : 1252-6576

Référence électronique

Алексей М. Лидов, « Видение Храма и Града », Cahiers du monde russe [Онлайн], 53/2-3 | 2012,

Выложить онлайн 01 juillet 2015, Наводить справки в 01 mai 2019. URL : http://

journals.openedition.org/monderusse/9380 ; DOI : 10.4000/monderusse.9380

Ce document a été généré automatiquement le 1 mai 2019.

2012 


\title{
ВИДЕНИЕ ХРАМА И ГРАДА
}

\author{
О ИЕРУСАЛИМСКОЙ СИМВОЛИКЕ СКУЛЬПТУРНЫХ ИКОН НА ФАСАДАХ \\ РУССКИХ ХРАМОВ ХІІ-ХІІІ ВЕКОВ
}

La vision de la ville et du temple: La symbolique de Jérusalem dans les icônes sculptées sur les façades des églises russes des XII et XIII ${ }^{e}$ siècles

A vision of city and temple: Jerusalem symbolism in sculptural icons on facades of twelfth-century Russian churches

\section{Алексей М. Лидов}

КАК СТАНОВИТСЯ ПОНЯТНЫМ В СВЕТЕ НОВЫХ ИССЛЕДОВАНИЙ, ВОСПРОИЗВЕДЕНИЕ СВЯТОЙ ЗЕМЛИ БЫЛО ОДНОЙ ИЗ ОСНОВ СРЕДНЕВЕКОВОЙ КУЛЬТУРЫ, СОХРАНЯВШЕЙ СВОЕ ЗНАЧЕНИЕ В САМЫХ ОТДАЛЕННЫХ ЧАСТЯХ ХРИСТИАНСКОГО МИРА ${ }^{1}$. ЭТО ЯВЛЯЛОСЬ НЕКИМ СТЕРЖНЕМ, ВОКРУГ КОТОРОГО ВЫСТРАИВАЛИСЬ ВСЕ ОСТАЛЬНЫЕ ФОРМЫ ЛИТУРГИЧЕСКОГО И ХУДОЖЕСТВЕННОГО ТВОРЧЕСТВА, ВКЛЮЧАЯ НЕ ТОЛЬКО СОЗДАНИЕ АРХИТЕКТУРНЫХ ПАМЯТНИКОВ, ИКОНОГРАФИЧЕСКИХ ПРОГРАММ И БОГОСЛУЖЕБНЫХ ПРЕДМЕТОВ, НО И ВОЗНИКНОВЕНИЕ НОВЫХ ОБРЯДОВ, ДРАМАТУРГИИ СВЕТА, СРЕДЫ ЗАПАХОВ ИЛИ СОБСТВЕННО ЛИТЕРАТУРНЫХ ТЕКСТОВ ${ }^{2}$. СТРЕМЛЕНИЕ ПРИОБЩИТЬСЯ $К$ ПРОСТРАНСТВУ, ГДЕ ПРОИЗОШЛИ ВАЖНЕЙШИЕ СОБЫТИЯ ИСТОРИИ СПАСЕНИЯ, ПОРОДИЛО МНОГОВЕКОВУЮ ТРАДИЦИЮ «НОВЫХ ИЕРУСАЛИМОВ», КОТОРЫЕ С РАННЕХРИСТИАНСКИХ ВРЕМЕН ПОЛУЧИЛИ РАСПРОСТРАНЕНИЕ И НА ВОСТОКЕ, И НА ЗАПАДЕ. РЕЧЬ ИДЕТ КАК ОБ ОСОБЫХ ПРОЕКТАХ ВОСПРОИЗВЕДЕНИЯ ИЕРУСАЛИМСКОГО ГРОБА ГОСПОДНЯ И ДРУГИХ СВЯТЫХ МЕСТ, ТАК И О БОЛЕЕ ОБЩЕЙ КОНЦЕПЦИИ, СОГЛАСНО КОТОРОЙ КАЖДЫЙ ХРАМ ВОСПРИНИМАЛСЯ КАК ОБРАЗ НОВОГО ИЕРУСАЛИМА, ЦАРСТВА НЕБЕСНОГО НА ЗЕМЛЕ.

В ПОЛНОЙ МЕРЕ СКАЗАННО ОТНОСИТСЯ К ДРЕВНЕЙ РУСИ. ПОНИМАНИЕ РУСИ КАК ИЗБРАННОЙ СВЯТОЙ ЗЕМЛИ И НОВОГО ИЗРАИЛЯ ОТНОСИТСЯ К ЧИСЛУ САМЫХ ВАЖНЫХ ИДЕОЛОГЕМ РУССКОЙ КУЛЬТУРЫ, НАШЕДШИХ ОТРАЖЕНИЕ УЖЕ В ДРЕВНЕЙШИХ ТЕКСТАХ, ТАКИХ КАК «СЛОВО О ЗАКОНЕ И БЛАГОДАТИ» МИТРОПОЛИТА ИЛАРИОНА ИЛИ ЗНАМЕНИТАЯ НАДПИСЬ НАД АЛТАРНОЙ АПСИДОЙ СОФИИ КИЕВСКОЙЗ. В ЭТИХ ТЕКСТАХ ГЛАВНЫЙ СОБОР РУСИ ОТОЖДЕСТВЛЯЕТСЯ СО СВЯТЫМ ГРАДОМ И НОВЫМ ИЕРУСАЛИМОМ, А КИЕВСКИЕ КНЯЗЬЯ ВЛАДИМИР И ЯРОСЛАВ СРАВНИВАЮТСЯ С ДАВИДОМ И СОЛОМОНОМ - 
ВЕЛИКИМИ СТРОИТЕЛЯМИ ГРАДА И ХРАМА. ОДНАКО ВЛИЯНИЕ ЭТОГО ТОПОСА НА ДРЕВНЕРУССКУЮ ВИЗУАЛЬНУЮ КУЛЬТУРУ ДОЛГОЕ ВРЕМЯ ОСТАВАЛОСЬ НЕОСМЫСЛЕННЫМ.

НА НАШ ВЗГЛЯД, ИМЕННО В ЭТОМ КОНТЕКСТЕ МОЖЕТ БЫТЬ ПРАВИЛЬНО ПОНЯТА СКУЛЬПТУРНАЯ ДЕКОРАЦИЯ ВЛАДИМИРО-СУЗДАЛЬСКИХ ХРАМОВ, КОТОРАЯ ПРИНАДЛЕЖИТ К САМЫМ ПРИМЕЧАТЕЛЬНЫМ И ШИРОКО ИЗВЕСТНЫМ ЯВЛЕНИЯМ ИСКУССТВА ДОМОНГОЛЬСКОЙ РУСЙ . СОЗДАННАЯ ПРИМЕРНО В ТЕЧЕНИЕ СТОЛЕТИЯ С СЕРЕДИНЫ ХІІ В. ПО СЕРЕДИНУ ХІІІ ВЕКА ПРОДОЛЖЕНИЯ В ДРЕВНЕРУССКОЙ ТРАДИЦИИ, РАВНО КАК И ПРЯМЫХ АНАЛОГИЙ В ИСКУССТВЕ ХРИСТИАНСКОГО МИРА. ЭТО ВО МНОГОМ УСЛОЖНИЛО ПОНИМАНИЕ ЕЕ ИКОНОГРАФИЧЕСКИХ ПРОГРАММ, КОТОРЫЕ ПРИ ВСЕМ РАЗНООБРАЗИИ КОНКРЕТНЫХ ПАМЯТНИКОВ XII-XIII ВВ. ОБНАРУЖИВАЮТ ТИПОЛОГИЧЕСКИ ОБЩИЕ ЧЕРТЫ, ПОЗВОЛЯЮЩИЕ ГОВОРИТЬ О ЕДИНОМ И ВПОЛНЕ СПЕЦИАЛЬНОМ СИМВОЛИЧЕСКОМ ЗАМЫСЛЕ.

ИСТОЛКОВАНИЕ ЭТОГО ЗАМЫСЛА УЖЕ НА ПРОТЯЖЕНИИ ПОЛУТОРА СТОЛЕТИЙ ЗАНИМАЕТ УМЫ ИССЛЕДОВАТЕЛЕЙ, ПРЕДЛОЖИВШИХ БОЛЬШОЕ ЧИСЛО ИНТЕРПРЕТАЦИЙ. МОЖНО ВЫДЕЛИТЬ ДВА ОСНОВНЫХ НАПРАВЛЕНИЯ. ОДНИ ИССЛЕДОВАТЕЛИ (В.ДОБРОХОТОВ, Ф. ХАЛЛЕ, Д.В. АЙНАЛОВ, В.Н. ЛАЗАРЕВ) ИСКАЛИ ОБЪЯСНЕНИЕ В ТЕКСТЕ ПСАЛМОВ ДАВИДА, СЧИТАЯ, ЧТО В СКУЛЬПТУРНОЙ ДЕКОРАЦИИ ВОПЛОТИЛАСЬ ОДНА ИЗ ГЛАВНЫХ ИДЕЙ ПСАЛТИРИ - «ВСЕ ДЫШАЩЕЕ ДА ХВАЛИТ ГОСПОДА!» (ПС. 150: 6) СТРЕМИЛИСЬ ИСТОЛКОВАТЬ СКУЛЬПТУРНЫЕ ОБРАЗЫ В РАМКАХ НАРОДНО-ФОЛЬКЛОРНОЙ ЯЗЫЧЕСКОЙ ТРАДИЦИИ, А ТАКЖЕ - СВЕТСКОЙ КУЛЬТУРЫ ${ }^{7}$ В В ЧАСТНОСТИ, НЕ ОТРИЦАЯ ЗНАЧЕНИЯ ПСАЛМОВ, МЫСЛЬ О СВЕТСКОМ ХАРАКТЕРЕ РЕЛЬЕФОВ ОТСТАИВАЛ А.Н. ГРАБАР. ЕГО АВТОРИТЕТНОЕ МНЕНИЕ ОКАЗАЛО ЗНАЧИТЕЛЬНОЕ ВЛИЯНИЕ НА ЗАПАДНУЮ НАУКУ Н.Н. ВОРОНИН КРИТИЧЕСКИ ОЦЕНИВАЛ ОБА НАПРАВЛЕНИЯ, ОН СВЯЗЫВАЛ СОДЕРЖАНИЕ СКУЛЬПТУРЫ С ПРОРОЧЕСТВАМИ ДАВИДА О ГОСУДАРСТВЕННО-ПОЛИТИЧЕСКИМИ ИДЕЯМИ. ПОСЛЕДНЯЯ ТОЧКА ЗРЕНИЯ БЫЛА РАЗВИТА И ОБОСНОВАНА В.П. ДАРКЕВИЧЕМ ${ }^{10}$.

5 Г.К. ВАГНЕР, МНОГО ЛЕТ ЗАНИМАВШИЙСЯ ИЗУЧЕНИЕМ ВЛАДИМИРО-СУЗДАЛЬСКОЙ СКУЛЬПТУРЫ, ПЫТАЛСЯ СОЕДИНИТЬ РАЗЛИЧНЫЕ ПОДХОДЫ, ОБЪЯСНЯЯ СВОЕОБРАЗИЕ ИКОНОГРАФИЧЕСКИХ ПРОГРАММ ПЕРЕОСМЫСЛЕНИЕМ РЕЛИГИОЗНЫХ СИМВОЛОВ В ДУХЕ НАРОДНЫХ ПРЕДСТАВЛЕНИЙ ${ }^{11}$. ПРЕДЛАГАЯ МНОГООБРАЗНЫЕ И СЛОЖНЫЕ ИНТЕРПРЕТАЦИИ, Г.К. ВАГНЕР ПРИЗНАВАЛ, ЧТО ПРОБЛЕМА ОСТАЕТСЯ НЕРЕШЕННОЙ ${ }^{12}$.

ПРИСТУПАЯ К РЕШЕНИЮ ДАННОЙ ЗАДАЧИ, НА НАШ ВЗГЛЯД, НЕОБХОДИМО ПОСТАВИТЬ ВОПРОСЫ, СВЯЗАННЫЕ С ОБЪЯСНЕНИЕМ НАИБОЛЕЕ ОРИГИНАЛЬНЫХ ЧЕРТ СКУЛЬПТУРНОЙ ДЕКОРАЦИИ:

1. ОТКУДА ВОЗНИКЛА ИДЕЯ РЕЗНОГО ДЕКОРА, ЗАПОЛНЯЮЩЕГО ВСЕ СТЕНЫ, И ЧТО ЯВИЛОСЬ ИМПУЛЬСОМ ДЛЯ ВЫНЕСЕНИЯ ИКОНОГРАФИЧЕСКОЙ ПРОГРАММЫ НА ФАСАДЫ ХРАМА? [илл. 1,4]

2. КАК ОБЪЯСНИТЬ ДОМИНИРУЮЩИЕ В ДЕКОРЕ МОТИВЫ «ЖЕНСКИХ ЛИКОВ», ЛЬВОВ, ПАЛЬМООБРАЗНЫХ ОРНАМЕНТОВ И ВОЗМОЖНОСТЬ ИХ СОЧЕТАНИЯ С ЧИСТО ИКОННЫМИ ОБРАЗАМИ? [ИЛЛ. 2]

3. В ЧЕМ СМЫСЛ ЦЕНТРАЛЬНОГО ОБРАЗА ДАВИДА НА ТРОНЕ, И КАКУЮ РОЛЬ ОН ИГРАЕТ В ИКОНОГРАФИЧЕСКОМ КОНТЕКСТЕ ХРАМОВОЙ ДЕКОРАЦИИ? [ИЛЛ. 3, 5] 
ПО НАШЕМУ МНЕНИЮ, КЛЮЧ К ОТВЕТУ НА ПЕРВЫЕ ДВА ВОПРОСА ДАЕТ ТЕКСТ ВЕТХОЗАВЕТНОГО ВИДЕНИЯ ИЕЗЕКИИЛЯ, В КОТОРОМ ОПИСЫВАЕТСЯ ЯВЛЕННЫЙ ПРОРОКУ XPAM:

ОТ ВЕРХА ДВЕРЕЙ КАК ВНУТРИ ХРАМА, ТАК И СНАРУЖИ, И ПО ВСЕЙ СТЕНЕ КРУГОМ, ВНУТРИ И СНАРУЖИ, БЫЛИ РЕЗНЫЕ ИЗОБРАЖЕНИЯ, СДЕЛАНЫ БЫЛИ ХЕРУВИМЫ И ПАЛЬМЫ; ПАЛЬМА МЕЖДУ ДВУМЯ ХЕРУВИМАМИ, И У КАЖДОГО ХЕРУВИМА ДВА ЛИЦА. С ОДНОЙ СТОРОНЫ К ПАЛЬМЕ ОБРАЩЕНО ЛИЦЕ ЧЕЛОВЕЧЕСКОЕ, А С ДРУГОЙ СТОРОНЫ К ПАЛЬМЕ ЛИЦЕ ЛЬВИНОЕ; ТАК СДЕЛАНО ВО ХРАМЕ КРУГОМ.(ИЕЗ. 41: 17-19)

ОБРАЗ ИЕЗЕКИИЛЯ ВОСПРОИЗВОДИТ ЧЕРТЫ ИСТОРИЧЕСКОГО ХРАМА СОЛОМОНА, ОПИСАННОГО В ТРЕТЬЕЙ КНИГЕ ЦАРСТВ (ГЛ. 6-7), НО ПРИ ЭТОМ ГОВОРИТСЯ НЕ О КОНКРЕТНОМ СООРУЖЕНИИ, А О ВИДЕНИИ НЕБЕСНОГО ХРАМА, КОТОРОЕ СТАЛО В ХРИСТИАНСКОЙ ТРАДИЦИИ ОДНИМ ИЗ ВАЖНЕЙШИХ ВЕТХОЗАВЕТНЫХ ОБРАЗОВ ГОРНЕГО ИЕРУСАЛИМА ${ }^{13}$.

ВИДЕНИЕ ИЕЗЕКИИЛЯ ВОСПРИНИМАЛОСЬ КАК ЯВЛЕННАЯ БОГОМ ИКОНА И ИМЕННО В ЭТОМ КАЧЕСТВЕ ПРИВОДИЛОСЬ ЗАЩИТНИКАМИ ИКОНОПОЧИТАНИЯ. В «СЛОВАХ» ИОАННА ДАМАСКИНА НАХОДИМ:

БОГ ПОКАЗАЛ ИЕЗЕКИИЛЮ ХРАМ, КОТОРЫЙ ИМЕЛ, ГОВОРИТ [ПИСАНИЕ], РЕЗНЫЕ ЛИЦА ЛЬВОВ И [ИЗОБРАЖЕНИЯ] ПАЛЬМ, И ЛЮДЕЙ, И ХЕРУВИМОВ, ОТ САМОГО ПОЛА ДАЖЕ ДО ПОТОЛКА ХРАМА. ${ }^{14}$

ТАКИМ ОБРАЗОМ, СКУЛЬПТУРНАЯ ДЕКОРАЦИЯ НА ФАСАДЕ ХРАМА, ВКЛЮЧАЮЩАЯ РЕЗНЫЕ ИЗОБРАЖЕНИЯ «ЛЬВОВ, ПАЛЬМ, ХЕРУВИМОВ И ЛЮДЕЙ», ИМЕЛА СОВЕРШЕННО ОПРЕДЕЛЕННЫЙ ЛИТЕРАТУРНЫЙ ИСТОЧНИК В СВЯЩЕННОМ ПИСАНИИ. ВЫЯВЛЕННЫЙ ИСТОЧНИК ПОЗВОЛЯЕТ ПРЕДПОЛОЖИТЬ, ЧТО ИНТЕРЕСУЮЩИЙ НАС СИМВОЛИЧЕСКИЙ ЗАМЫСЕЛ СОСТОЯЛ В УПОДОБЛЕНИИ ВЛАДИМИРО-СУЗДАЛЬСКИХ ЦЕРКВЕЙ ХРАМУ ИЗ ВИДЕНИЯ ИЕЗЕКИИЛЯ И В ВОПЛОЩЕНИИ ИДЕИ НЕБЕСНОГО ИЕРУСАЛИМА, ИКОННЫЙ ОБРАЗ КОТОРОГО НА ФАСАДЕ ЦЕРКВИ ДОЛЖЕН БЫЛ ЯВСТВЕННО НАПОМНИТЬ О ХРАМЕ КАК «ЦАРСТВИИ НЕБЕСНОМ НА ЗЕМЛЕ» И «ГОРНЕМ ГРАДЕ», ГДЕ В КОНЦЕ ВРЕМЕН ОБРЕТУТ СПАСЕНИЕ ПРАВЕДНИКИ.

11 НА НАШ ВЗГЛЯД, ВИДЕНИЕ ИЕЗЕКИИЛЯ ПОЗВОЛЯЕТ ПОНЯТЬ НЕ ТОЛЬКО КОНЦЕПЦИЮ ИЗОБРАЗИТЕЛЬНОГО РЕШЕНИЯ В ЦЕЛОМ, НО И ИСТИННЫЙ СМЫСЛ НАИБОЛЕЕ ВАЖНЫХ МОТИВОВ. К ИХ ЧИСЛУ ПРИНАДЛЕЖАТ ТАК НАЗЫВАЕМЫЕ «ЖЕНСКИЕ ЛИКИ» ИЛИ «МАСКИ», [ИЛЛ. 2] В КОТОРЫХ ВИДЕЛИ «ПЕРЕЖИТОЧНЫЕ ФОРМЫ СЛАВЯНСКОГО КУЛЬТА БОГИНИ-МАТЕРИ» (М.В. АЛПАТОВ, В.Н. ЛАЗАРЕВ) ${ }^{15}$, ИЗОБРАЖЕНИЯ ДЕВ, ИДУЩИХ ЗА ДЩЕРЬЮ ЦАРЯ (ПС. 44: 15-16), «СИМВОЛЫ ДЕВЫ МАРИИ», СВЯЗАННЫЕ С ПОСВЯЩЕНИЕМ ХРАМА БОГОМАТЕРИ (Н.Н. ВОРОНИН $)^{16}$, И ДАЖЕ ПОЭТИЧЕСКИЕ ОБРАЗЫ, СИМВОЛИЗИРУЮЩИЕ НАРОД ВЛАДИМИРО-СУЗДАЛЬСКОЙ ЗЕМЛИ (Г.К. ВАГНЕР) ${ }^{17}$.

ОДНАКО, ПО ВСЕЙ ВИДИМОСТИ, «ЛИКИ» ПРЕДСТАВЛЯЛИ ОБРАЗЫ ХЕРУВИМОВ, КОТОРЫЕ, СОГЛАСНО ВИДЕНИЮ ИЕЗЕКИИЛЯ, РАСПОЛАГАЛИСЬ «ПО ВСЕЙ СТЕНЕ КРУГОМ» В ХРАМЕ НЕБЕСНОГО ИЕРУСАЛИМА. СОХРАНИВШИЕСЯ ИЗОБРАЖЕНИЯ (ХРАМ В БОГОЛЮБОВЕ, ПЕРВЫЙ УСПЕНСКИЙ СОБОР, А ТАКЖЕ ЦЕРКОВЬ ПОКРОВА НА НЕРЛИ), НАХОДЯТ ИКОНОГРАФИЧЕСКИЕ ПАРАЛЛЕЛИ В ТРАКТОВКЕ НЕБЕСНЫХ СИЛ В ХРИСТИАНСКОМ ИСКУССТВЕ ХІ-ХІІ ВВ. ${ }^{18}$. ОТМЕТИМ СВОЕОБРАЗНУЮ ПРИЧЕСКУ С НИСПАДАЮЩИМИ И КАК БЫ УЛОЖЕННЫМИ В ДВЕ КОСЫ ВОЛОСАМИ, ТРАПЕЦИЕВИДНЫЕ ВОРОТЫ, ДИАДЕМЫ И ЛЕНТЫ. НАИБОЛЕЕ БЛИЗКИ СКУЛЬПТУРНЫМ ОБРАЗАМ АНГЕЛЬСКИЕ ЛИКИ-МАСКИ В ЦЕНТРЕ ИЗОБРАЖЕНИЙ ШЕСТИКРЫЛЫХ ХЕРУВИМОВ, СЕРАФИМОВ И ТЕТРАМОРФОВ, 
КОТОРЫЕ МОГЛИ БЫТЬ ПОКАЗАНЫ КАК С НИМБАМИ, ТАК И БЕЗ НИХ ${ }^{19}$. ХАРАКТЕРНО, ЧТО НА ЧЕТЫРЕХЛИКОЙ КАПИТЕЛИ ИЗ БОГОЛЮБОВА ПОХОЖИЕ ЛИКИ ИМЕЮТ НИМБЫ ${ }^{20}-$ ПРЯМОЕ УКАЗАНИЕ НА ИХ ПРИНАДЛЕЖНОСТЬ К НЕБЕСНЫМ СИЛАМ. ОТМЕТИМ ТАКЖЕ, ЧТО САМО ИЗОБРАЖЕНИЕ АНГЕЛОВ НА КАПИТЕЛИ ДОСТАТОЧНО ТРАДИЦИОННО.

В РОМАНСКОЙ ИКОНОГРАФИИ НЕБЕСНОГО ИЕРУСАЛИМА ГОРОД-ХРАМ ОКРУЖЕН СВОЕОБРАЗНЫМ ПОЯСОМ ИЗ АНГЕЛЬСКИХ ОБРАЗОВ. ИНОГДА ЭТО ПРОСТО ЛИКИ В АРКАХВРАТАХ ГОРОДСКИХ СТЕН (ОТКР. 21: 12), К ПРИМЕРУ, НА ЗНАМЕНИТОЙ ФРЕСКЕ ИЗ САН ПЬЕТРО АЛЬ МОНТЕ В ЧИВАТЕ (ХІ В.) ${ }^{21,17}$. В ЭТОЙ СВЯЗИ ПРИМЕЧАТЕЛЬНО, ЧТО ВО ВЛАДИМИРО-СУЗДАЛЬСКОЙ СКУЛЬПТУРЕ ХІІІ В. ПОЯВЛЯЮТСЯ «ЛИКИ», ВПИСАННЫЕ В АРОЧКИ ${ }^{22}$. В ОДНОЙ ИЗ ПЕРВЫХ ПРОГРАММ ЦЕРКВИ ПОКРОВА НА НЕРЛИ «ЛИКИ» ПОКАЗАНЫ ПО СЕМЬ НА КАЖДОЙ ИЗ ТРЕХ СТЕН ${ }^{23}$, ОНИ ОБРАЗУЮТ СВОЕГО РОДА ДОПОЛНИТЕЛЬНЫЙ ФРИЗ, РАСПОЛОЖЕННЫЙ НАД АРКАТУРНО-КОЛОНЧАТЫМ ПОЯСОМ [ИЛЛ. 1]. ЭТА ОСОБЕННОСТЬ ТАКЖЕ МОЖЕТ БЫТЬ ПРОЯСНЕНА БЛАГОДАРЯ ОБРАЩЕНИЮ К ИКОНОГРАФИИ НЕБЕСНОГО ИЕРУСАЛИМА В РОМАНСКОМ ИСКУССТВЕ. В РЯДЕ МИНИАТЮР (НАПРИМЕР, В АПОКАЛИПСИСЕ СЕН СЕВЕРА ХІ В. - ПАРИЖ, НАЦ. Б-КА, lat. 8878, fol. 207v-208) ${ }^{24}$ ОГЛАВНЫЕ ИЗОБРАЖЕНИЯ АНГЕЛОВ ПОКАЗАНЫ НЕПОСРЕДСТВЕННО НАД РАСПОЛОЖЕННЫМИ ПО ПЕРИМЕТРУ АРКАМИ, ОБРАЗУЮЩИМИ ГОРОДСКУЮ СТЕНУ, ТОГДА КАК В САМИХ АРКАХ ПРЕДСТАВЛЕНЫ ДВЕНАДЦАТЬ АПОСТОЛОВ. ЕСЛИ НАШЕ ИСТОЛКОВАНИЕ ВЕРНО, ТО ВОЗНИКАЕТ ВОЗМОЖНОСТЬ ПОНЯТЬ ИЗНАЧАЛЬНЫЙ СИМВОЛИЧЕСКИЙ СМЫСЛ АРКАТУРНО-КОЛОНЧАТОГО ПОЯСА. ВЕРОЯТНО, ОН БЫЛ ПРИЗВАН СОЗДАТЬ ОБРАЗ ИЕРУСАЛИМСКОЙ СТЕНЫ, КОТОРАЯ В РОМАНСКИХ ИЗОБРАЖЕНИЯХ НЕБЕСНОГО ГРАДА ТРАДИЦИОННО ПОКАЗЫВАЕТСЯ В ВИДЕ СПЛОШНОЙ АРКАДЫ, ОКРУЖАЮЩЕЙ ГОРОД 25 . ЗНАМЕНАТЕЛЬНО И ПОЯВЛЕНИЕ ОБРАЗОВ СВЯТЫХ В АРКАТУРЕ НА СТЕНАХ ВЛАДИМИРО-СУЗДАЛЬСКИХ ЦЕРКВЕЙ. КАК И АПОСТОЛЫ В РОМАНСКИХ МИНИАТЮРАХ, ОНИ ВЫСТУПАЮТ В КАЧЕСТВЕ ОБИТАТЕЛЕЙ И ЗАЩИТНИКОВ ГОРНЕГО ИЕРУСАЛИМА, А АРКАТУРНЫЙ ПОЯС СО СВЯТЫМИ СОЗДАЕТ СИМВОЛИЧЕСКУЮ ГРАНИЦУ ХРАМА КАК ВОПЛОЩЕННОГО НЕБЕСНОГО ГРАДА ${ }^{26}$. НЕ КАЖЕТСЯ СЛУЧАЙНЫМ И ЧИСЛО ЛИКОВ НА СТЕНАХ ЦЕРКВИ ПОКРОВА НА НЕРЛИ, ВЕРОЯТНО, ОНО НАПОМИНАЕТ О «СЕМИ ДУХАХ БОЖЬИХ», КОТОРЫЕ, СОГЛАСНО АПОКАЛИПСИСУ, СОПРОВОЖДАЮТ ГОСПОДА В КОНЦЕ ВРЕМЕН (ОТКР. 4: 5; 5: 6; 8: 6) ${ }^{27}$. САКРАЛЬНОЕ ЧИСЛО ЗДЕСЬ МОЖЕТ ОБОЗНАЧАТЬ ВРЕМЯ ЯВЛЕНИЯ НЕБЕСНОГО ИЕРУСАЛИМА, СХОДЯЩЕГО С НЕБЕС. ЗНАМЕНАТЕЛЬНО, ЧТО НА РОМАНСКИХ КАДИЛЬНИЦАХ, СДЕЛАННЫХ В ВИДЕ НЕБЕСНОГО ИЕРУСАЛИМА, ОБРАЗЫ АНГЕЛОВ СОЧЕТАЮТСЯ С ПАЛЬМОВИДНЫМ ОРНАМЕНТОМ, ИЗОБРАЖЕНИЯМИ ЛЬВОВ И ЛЬВИНЫХ МАСОК [ИЛЛ. 6]. ПОМИМО 20 СОХРАНИВШИХСЯ КАДИЛЬНИЦ ХІІ В. ${ }^{28}$ ДО НАС ДОШЛО И ПОДРОБНОЕ ОПИСАНИЕ ИХ ИДЕАЛЬНОЙ ИКОНОГРАФИИ, ИЗЛОЖЕННОЕ В ГЛ. 59-60 ЗНАМЕНИТОГО «МАНУСКРИПТА ТЕОФИЛА ${ }^{29}$. В ТРАКТАТЕ ГОВОРИТСЯ, ЧТО КАДИЛЬНИЦА ДЕЛАЕТСЯ «В ВИДЕ ГОРОДА, УВИДЕННОГО ПРОРОКОМ НА ГОРЕ», НА БАШНЯХ ГОРОДА ДОЛЖНЫ БЫТЬ «ПОЯСНЫЕ ИЗОБРАЖЕНИЯ ХЕРУВИМОВ, КАК БЫ СИДЯЩИХ НА СВОИХ КРЫЛЬЯХ», ВНИЗУ - АРКИ С ЕВАНГЕЛИСТАМИ СРЕДИ «АНГЕЛОВ И ЗВЕРЕЙ», МЕЖДУ АРКАМИ - ЛИТЫЕ ГОЛОВЫ ЛЬВОВ ${ }^{30}$. ГОВОРИТСЯ И О ДРУГОМ ПОЯСЕ «ИЗОБРАЖЕНИЙ АНГЕЛОВ СО ЩИТАМИ И КОПЬЯМИ, КАК БЫ ПОСТАВЛЕННЫХ ДЛЯ ОХРАНЫ СТЕН ${ }^{31}$. ДЛЯ НАС ОСОБЕННО ВАЖНО, ЧТО ТЕОФИЛ В СВОЕМ РУКОВОДСТВЕ ХІ В. ПРЯМО УКАЗЫВАЕТ В КАЧЕСТВЕ ОБРАЗЦА ДРАГОЦЕННОЙ КАДИЛЬНИЦЫ «ГОРОД, УВИДЕННЫЙ ПРОРОКОМ НА ГОРЕ», Т. Е. ГОРОД-ХРАМ, ОПИСАННЫЙ В ВИДЕНИИ ИЕЗЕКИИЛЯ (ИЕЗ. 40-49). 
В ДЕКОРЕ ЛИТУРГИЧЕСКОЙ УТВАРИ ХІ-ХІІ ВВ. МОЖНО НАЙТИ АНАЛОГИИ НЕ ТОЛЬКО ФРИЗУ АНГЕЛЬСКИХ ОБРАЗОВ, НО И ДРУГИМ ИКОНОГРАФИЧЕСКИМ МОТИВАМ ВЛАДИМИРО-СУЗДАЛЬСКОЙ РЕЗЬБЫ ${ }^{32}$. ОТМЕТИМ, ЧТО РЕЧЬ ИДЕТ О РЕЛЬЕФНЫХ (ЛИТЫХ И ЧЕКАННЫХ) ИЗОБРАЖЕНИЯХ, ЧТО УСИЛИВАЕТ АНАЛОГИЮ С МОНУМЕНТАЛЬНОЙ СКУЛЬПТУРОЙ. КАЖЕТСЯ ПРИНЦИПИАЛЬНО ВАЖНЫМ, ЧТО РОМАНСКИЕ МАСТЕРА, СОЗДАВАЯ В МАЛЫХ ФОРМАХ ОБРАЗ НЕБЕСНОГО ИЕРУСАЛИМА, ОБРАЩАЮТСЯ К ВЕТХОЗАВЕТНЫМ ПРООБРАЗАМ И ВИДЕНИЯМ (В ОТЛИЧИЕ ОТ ФРЕСОК И МИНИАТЮР, ГДЕ ПРЕИМУЩЕСТВЕННО ИСПОЛЬЗУЕТСЯ ТЕКСТ АПОКАЛИПСИСА). ИХ ПРИВЛЕКАЕТ КОНКРЕТНОСТЬ ОБРАЗА ХРАМА СОЛОМОНА, ВОЗМОЖНОСТЬ ИЗОБРАЖЕНИЯ ГОРОДА-ХРАМА В ВИДЕ ЦЕРКОВНОГО ЗДАНИЯ. НАИБОЛЕЕ ВАЖНУЮ ТЕМУ ВЛАДИМИРО-СУЗДАЛЬСКОЙ СКУЛЬПТУРНОЙ ДЕКОРАЦИИ СОСТАВЛЯЕТ ПОВТОРЯЮЩИЙСЯ НА ВСЕХ ФАСАДАХ ОБРАЗ ЦАРЯ ДАВИДА НА ТРОНЕ ${ }^{33}$ [ИЛЛ. 3, 5], КОТОРЫЙ ЗАМЕНЯЕТ ЗДЕСЬ ТРАДИЦИОННОЕ ДЛЯ ИКОНОГРАФИИ НЕБЕСНОГО ИЕРУСАЛИМА ИЗОБРАЖЕНИЕ ХРИСТА-КОСМОКРАТОРА, ВОССЕДАЮЩЕГО НА ТРОНЕ, СФЕРЕ ИЛИ НЕБЕСНОМ СВОДЕ. ЦАРЬ, ПСАЛМОПЕВЕЦ И ПОМАЗАННИК ДАВИД ПРООБРАЗУЕТ ХРИСТА. ЭТО ДРЕВНЕЕ СОПОСТАВЛЕНИЕ НАШЛО ЯРКОЕ ВОПЛОЩЕНИЕ В ПЕРВОЙ МИНИАТЮРЕ ХЛУДОВСКОЙ ПСАЛТИРИ ІХ В., ГДЕ ЮНЫЙ ХРИСТОС В МЕДАЛЬОНЕ ПОКАЗАН НАД ДАВИДОМ НА ТРОНЕ (ИЗОБРАЖЕНИЕ ОБРАМЛЯЕТ АРКА, СИМВОЛИЗИРУЮЩАЯ ХРАМ) ${ }^{34}$ - СОПОСТАВЛЕНИЕ ОБРАЗОВ ХРИСТА И ДАВИДА НЕОДНОКРАТНО ВСТРЕЧАЕТСЯ В ИЛЛЮСТРАЦИЯХ ПСАЛТЫРЕЙ КАК В ВИЗАНТИИ, ТАК И НА ЗАПАДЕ. К ПРИМЕРУ, ВО ФРОНТИСПИСЕ ПСАЛТЫРИ ХІ В. ИЗ ВАТИКАНСКОЙ БИБЛИОТЕКИ (Vat. Bibl. Cod. gr. 752, fol. 18v) ХРИСТОС НА ТРОНЕ ПОКАЗАН НАД СТОЯЩИМ ДАВИЛОМ, КОТОРЫЙ ОБЛАЧЕН В ИМПЕРАТОРСКИЕ ОДЕЯНИЯ С ЛОРОМ ${ }^{35}$. ПРИМЕЧАТЕЛЬНО, ЧТО И ПО СТОРОНАМ ОТ ТРОННОГО ХРИСТА ИЗОБРАЖЕНЫ СЦЕНЫ ЯВЛЕНИЯ АНГЕЛА ЖЕНАМ-МИРОНОСИЦАМ И ВОСКРЕШЕНИЯ ЛАЗАРЯ, Т. Е. НЕДВУСМЫСЛЕННО ВЫРАЖЕНА МЫСЛЬ О ГРЯДУЩЕМ ВОСКРЕСЕНИИ, ПОДЧЕРКИВАЮЩАЯ ТЕОФАНИЧЕСКИЙ ХАРАКТЕР ОБРАЗОВ ХРИСТА И ДАВИДА.

СКУЛЬПТУРНЫЕ ОБРАЗЫ ХІІ В. ПОЗВОЛЯЮТ ОТМЕТИТЬ ТРИ АСПЕКТА ЭТОЙ ПРЕОБРАЗОВАТЕЛЬНОЙ СИМВОЛИКИ: ПРОСЛАВЛЯЮЩИЙ, ЛИТУРГИЧЕСКИЙ И ЭСХАТОЛОГИЧЕСКИЙ. ПОЗА, ТРОН, НИМБ И КОРОНА ДАВИДА ГОВОРЯТ О СВЯТОМ ЦАРЕ-КОСМОКРАТОРЕ. ЛЕНТА, ОПОЯСЫВАЮЩАЯ СТИХАРЬ, В ИЗОБРАЖЕНИЯХ ЦЕРКВИ ПОКРОВА НА НЕРЛИ НАПОМИНАЕТ КАК ОБ ИМПЕРАТОРСКИХ, ТАК И ЛИТУРГИЧЕСКИХ ОДЕЯНИЯХ ${ }^{36}$. ПСАЛТИРЬ В РУКЕ ЗНАМЕНУЕТ ПЕСНОПЕНИЯ И ХРАМОВОЕ БОГОСЛУЖЕНИЕ ${ }^{37}$. ОРАТОРСКОЕ БЛАГОСЛОВЕНИЕ ОТСТАВЛЕННОЙ И ПОДНЯТОЙ РУКОЙ ВЫЗЫВАЕТ В ПАМЯТИ ТЕОФАНИЧЕСКИЕ ОБРАЗЫ ХРИСТА ${ }^{38}$. ЭТА СИМВОЛИКА НАХОДИТ КОНЦЕНТРИРОВАННОЕ ВЫРАЖЕНИЕ В ОБРАЗЕ ПРЕСТОЛА УГОТОВАННОГО НАД ГОЛОВОЙ ДАВИДА В ЦЕНТРАЛЬНОЙ ЗАКОМАРЕ ЮЖНОГО ФАСАДА ДМИТРИЕВСКОГО СОБОРА. ПРЕСТОЛ НЕ ТОЛЬКО СИМВОЛ ТРОИЦЫ, ОТ КОТОРОГО НИСХОДИТ ГОЛУБЬ СВЯТОГО ДУХА, НО И ВОПЛОЩЕННАЯ ИДЕЯ АЛТАРЯ-ЖЕРТВЕННИКА, А ТАКЖЕ ИЗОБРАЖЕНИЕ ПРЕСТОЛА, УГОТОВАННОГО ДЛЯ ВЫСШЕГО СУДЬИ ${ }^{39}$. ПО СТОРОНАМ ОТ ПРЕСТОЛА УГОТОВАННОГО ПРЕДСТАВЛЕНЫ ДВЕ СИДЯЩИЕ ФИГУРЫ В НИМБАХ И С РАСКРЫТЫМИ СВИТКАМИ В РУКАХ. Г.К. ВАГНЕР ВИДЕЛ В НИХ ИЗОБРАЖЕНИЯ ПРОРОКА НАФАНА И ЖРЕЦА САДОКА, ДОБИВШИХСЯ ВОСШЕСТВИЯ СОЛОМОНА НА ЦАРСКИЙ ТРОН ${ }^{40}$. ОДНАКО БОЛЕЕ ВЕРОЯТНО, ЧТО ВСЕ ИЗОБРАЖЕНИЯ ОБЪЕДИНЯЕТ ИДЕЯ ТЕОФАНИИ И, СООТВЕТСТВЕННО, ОКОЛО ТЕОФАНИЧЕСКИХ ОБРАЗОВ ПРЕСТОЛА УГОТОВАННОГО И ДАВИДА ПОЯВЛЯЮТСЯ ИЗОБРАЖЕНИЯ ПРОРОКОВ ИСАЙИ И ИЕЗЕКИИЛЯ, ОСТАВИВШИХ НАИБОЛЕЕ ВАЖНЫЕ ОПИСАНИЯ ТЕОФАНИЧЕСКИХ ВИДЕНИЙ ${ }^{41}$. 

КЛЮЧЕВОЙ ДЛЯ ПОНИМАНИЯ ОБРАЗА ДАВИДА В КОНТЕКСТЕ СИМВОЛИКИ НОВОГО ИЕРУСАЛИМА, СХОДЯЩЕГО С НЕБЕС В КОНЦЕ ВРЕМЕН ${ }^{42}$. ДАВИД ИМЕЕТ ОСОБЫЕ ПРАВА НА ЭТОТ КОНТЕКСТ, ПОСКОЛЬКУ ИЕРУСАЛИМ - ГРАД ДАВИДА. ИМЕННО ОН СДЕЛАЛ ЕГО ГОРОДОМ ВЕЛИКОГО ЦАРЯ, СВЯТЫМ МЕСТОМ, ГДЕ БЫЛА УСТАНОВЛЕНА СКИНИЯ И ПО ЗАМЫСЛУ ДАВИДА ВОЗВЕДЕН ХРАМ ЕГО СЫНОМ СОЛОМОНОМ ${ }^{43}$. ДАВИД - ОДИН ИЗ САМЫХ ВАЖНЫХ ПРЕДВОЗВЕСТНИКОВ НОВОГО ИЕРУСАЛИМА, ЕГО ПРОРОЧЕСКИЕ ПСАЛМЫ ТРАДИЦИОННО ИЛЛЮСТРИРУЮТСЯ ИЗОБРАЖЕНИЯМИ НЕБЕСНОГО ГРАДА ${ }^{44}$. В РОМАНСКОЙ ИКОНОГРАФИИ ДАВИД НА ТРОНЕ ИНОГДА ИЗОБРАЖАЕТСЯ В ОБРАМЛЕНИИ СТЕН НЕБЕСНОГО ИЕРУСАЛИМА (ДИЖОНСКАЯ БИБЛИЯ, Л. 13 ОБ., 1098-1109 ГГ.).45, ЧТО ПОЗВОЛЯЕТ ГОВОРИТЬ О КОНЦЕПТУАЛЬНОЙ ПОДГОТОВЛЕННОСТИ ПРОГРАММЫ ВЛАДИМИРО-СУЗДАЛЬСКИХ ХРАМОВ.

И ВСЕ ЖЕ ЗАМЕНА ХРИСТА ОБРАЗОМ ДАВИДА В ИКОНЕ НЕБЕСНОГО ИЕРУСАЛИМА ЯВЛЯЕТСЯ СПЕЦИАЛЬНЫМ И РЕДКИМ РЕШЕНИЕМ, КОТОРОЕ СТАНОВИТСЯ БОЛЕЕ ПОНЯТНЫМ В СВЕТЕ ИДЕЙ ЗАКАЗЧИКА ПЕРВЫХ ВЛАДИМИРО-СУЗДАЛЬСКИХ ХРАМОВ. КАК ИЗВЕСТНО, ДЕЯТЕЛЬНОСТЬ АНДРЕЯ БОГОЛЮБСКОГО БЫЛА НАПРАВЛЕНА НА УТВЕРЖДЕНИЕ ВЛАДИМИРА В КАЧЕСТВЕ СТОЛИЦЫ РУСИ И ЦЕНТРА НОВОЙ МИТРОПОЛИИ ${ }^{46}$. КАЖЕТСЯ ВЕСЬМА ВЕРОЯТНЫМ УЖЕ ВЫСКАЗЫВАВШЕЕСЯ ПРЕДПОЛОЖЕНИЕ, ЧТО КНЯЗЬ МОГ ОТОЖДЕСТВЛЯТЬ СЕБЯ С ДАВИДОМ, СОЗДАЮЩИМ ИЕРУСАЛИМ ${ }^{47}$. ОТГОЛОСКИ ЭТОГО ГЛОБАЛЬНОГО ЗАМЫСЛА МОГУТ БЫТЬ ЗАМЕЧЕНЫ В ЛЕТОПИСНЫХ СВИДЕТЕЛЬСТВАХ, ЦЕРКОВНОЙ КНИЖНОСТИ, ТОПОНИМИКЕ И АРХИТЕКТУРНО-АРХЕОЛОГИЧЕСКИХ РЕАЛИЯХ ${ }^{48}$ . СОВРЕМЕННИКИ СРАВНИВАЛИ ГЛАВНЫЕ СОБОРЫ АНДРЕЯ БОГОЛЮБСКОГО СО СВЯТАЯ СВЯТЫХ - ХРАМОМ СОЛОМОНА, ПРИ ЭТОМ САМ КНЯЗЬ СРАВНИВАЛСЯ И С ДАВИДОМ, И С СОЛОМОНОМ $^{49}$ В СООТВЕТСТВИИ С СРЕДНЕВЕКОВОЙ ТРАДИЦИЕЙ, РАССМАТРИВАВШЕЙ ЦАРСТВЕННЫХ ПРЕДКОВ ХРИСТА, ОТЦА И СЫНА, КАК АВТОРОВ ОДНОГО ВЕЛИКОГО ПРОЕКТА ПО СОЗДАНИЮ ГРАДА И ХРАМА ${ }^{50}$.

КНЯЗЬ АНДРЕЙ СТРОИТ СВОЮ РЕЗИДЕНЦИЮ В БОГОЛЮБОВЕ КАК СВЯЩЕННЫЙ «ГРАД», СОСТОЯЩИЙ ИЗ ДВОРЦА И ХРАМА, ПО СЛОВАМ СОВРЕМЕННИКОВ,

УПОДОБИСЯ ЦАРЮ СОЛОМОНУ, ЯКО ДОМЪ ГОСПОДУ БОГУ И ЦЕРКОВЬ ПРЕСЛАВНУ СЕЯ СВЯТЫЯ БОГОРОДИЦА РОЖДЕСТВА ПОСРЕДЕ ГОРОДА КАМЕНУ СОЗДАВЪ БОГОЛЮБОМЪ И УДИВИ Ю ПАЧЕ ВСИХЪ ЦЕРКВИИ; ПОДОБНА ПОЕ СВЯТАЯ СВЯТЫХЪ, ЮЖЕ БЕ СОЛОМОН ЦАРЬ ПРЕМУДРЫЙ СОЗДАЛЪ, ТАКО И СИИ КНЯЗЬ БЛАГОВЕРНЫЙ АНДРЕЙ И СТВОРИ ЦЕРКОВЬ СИЮ В ПАМЯТЬ СОБЕ... ${ }^{51}$

В ДАННОЙ СВЯЗИ ПРИМЕЧАТЕЛЬНО, ЧТО САМОЕ ВОЗВЫШЕННОЕ МЕСТО В БОГОЛЮБОВЕ НОСИЛО ДРЕВНЕЕ НАЗВАНИЕ «СИОНЫ ${ }^{52}$. СТРОЯ СВОЮ РЕЗИДЕНЦИЮ КАК ДВОРЕЦ-ХРАМ И «СВЯТОЙ ГРАД», АНДРЕЙ БОГОЛЮБСКИЙ СЛЕДОВАЛ ДРЕВНЕЙ ХРИСТИАНСКОЙ ТРАДИЦИИ, НАИБОЛЕЕ ИЗВЕСТНЫЙ ПРИМЕР КОТОРОЙ - СТРОИТЕЛЬСТВО КАРЛОМ ВЕЛИКИМ НА РУБЕЖЕ VIII-IX ВВ. СВОЕЙ РЕЗИДЕНЦИИ В ААХЕНЕ, ЗАДУМАННОЙ КАК ЗЕМНОЙ ОБРАЗ НЕБЕСНОГО ИЕРУСАЛИМА ${ }^{53}$.

ВИДИМО, СКУЛЬПТУРНАЯ ИКОНА НЕБЕСНОГО ИЕРУСАЛИМА, ВЫНЕСЕННАЯ НА ФАСАДЫ ХРАМОВ, БЫЛА ВАЖНОЙ ЧАСТЬЮ ИДЕЙНОГО ЗАМЫСЛА АНДРЕЯ БОГОЛЮБСКОГО. ИКОНОГРАФИЧЕСКИ ОНА, СКОРЕЕ ВСЕГО, БЫЛА РАЗРАБОТАНА РОМАНСКИМИ МАСТЕРАМИ, ПРИСЛАННЫМИ, ПО СВИДЕТЕЛЬСТВУ В.Н.ТАТИЩЕВА, ЩОТ ИМПЕРАТОРА ФРИДЕРИКА ПЕРВОГО, С КОТОРЫМ АНДРЕЙ В ДРУЖБЕ БЫЛ.... ${ }^{54}$. ОБ ЭТОМ СВИДЕТЕЛЬСТВУЮТ ВСЕ РАНЕЕ ОТМЕЧЕННЫЕ ИКОНОГРАФИЧЕСКИЕ ПАРАЛЛЕЛИ В РОМАНСКИХ ИЗОБРАЖЕНИЯХ НЕБЕСНОГО ИЕРУСАЛИМА. ОДНАКО ОТСУТСТВИЕ ПРЯМЫХ ЗАПАДНЫХ АНАЛОГИЙ ДЕЛАЕТ

Cahiers du monde russe, 53/2-3 | 2012 
ВЕСЬМА ВЕРОЯТНЫМ РЕДАКТОРСКОЕ УЧАСТИЕ САМОГО ВЫСОКООБРАЗОВАННОГО КНЯЗЯ АНДРЕЯ, КОТОРЫЙ УДЕЛЯЛ ЗНАЧИТЕЛЬНОЕ ВНИМАНИЕ СОЗДАНИЮ ОСОБОЙ РЕЛИГИОЗНОПОЛИТИЧЕСКОЙ ИДЕОЛОГИИ СВОЕГО КНЯЖЕСТВА ${ }^{55}$.

ПОДОБНАЯ ИКОНОГРАФИЧЕСКАЯ ПРОГРАММА, БЕСПРЕЦЕДЕНТНАЯ В ВИЗАНТИЙСКОЙ ТРАДИЦИИ, МОГЛА ПОЯВИТЬСЯ ТОЛЬКО В ЭПОХУ ОСЛАБЛЕНИЯ КОНТРОЛЯ СО СТОРОНЫ ПРАВОСЛАВНОЙ ИЕРАРХИИ. НАПОМНИМ, ЧТО НА ВРЕМЯ СТРОИТЕЛЬСТВА ПЕРВЫХ СОБОРОВ ПРИХОДИТСЯ КОНФЛИКТ КНЯЗЯ АНДРЕЯ С КОНСТАНТИНОПОЛЬСКИМ ПАТРИАРХАТОМ: ИЗГНАНИЕ ГРЕЧЕСКОГО ЕПИСКОПА ЛЕОНА, ОТКЛОНЕННОЕ ПРОШЕНИЕ ОБ УЧРЕЖДЕНИИ МИТРОПОЛИИ, САМОУПРАВНОЕ ПОСТАВЛЕНИЕ В ЕПИСКОПЫ ФЕОДОРА, ЗАТЕМ ОСУЖДЕННОГО НА СМЕРТЬ В КИЕВЕ ${ }^{56}$. ВИДИМО, ТОЛЬКО В ЭТОЙ СИТУАЦИИ «ЛАТИНСКИЕ ОБРАЗЫ» МОГЛИ ПРИОБРЕСТИ СТАТУС ПРОГРАММНОЙ ИКОНЫ, В КОТОРОЙ ОТРАЗИЛИСЬ КАК ЭСХАТОЛОГИЧЕСКИЕ ЧАЯНИЯ, ТАК И ИМПЕРСКИЕ АМБИЦИИ ЧЕСТОЛЮБИВОГО КНЯЗЯ ${ }^{57}$.

ОДНИМ ИЗ ЗРИМЫХ ИМПУЛЬСОВ К СОЗДАНИЮ СКУЛЬПТУРНОЙ ДЕКОРАЦИИ МОГЛА СТАТЬ РОМАНСКАЯ ЛИТУРГИЧЕСКАЯ УТВАРЬ, КОТОРУЮ, ВОЗМОЖНО, ПРИНЕСЛИ С СОБОЙ МАСТЕРА «ОТ НЕМЕЦ» В КАЧЕСТВЕ ДАРА ФРИДРИХА БАРБАРОССЫ ${ }^{58}$. ПО ЗАКАЗУ ИМПЕРАТОРА СОЗДАВАЛИСЬ ЦЕРКОВНЫЕ ПРЕДМЕТЫ, ВОПЛОЩАВШИЕ ОБРАЗ НЕБЕСНОГО ИЕРУСАЛИМА, К САМЫМ ИЗВЕСТНЫМ ПРИНАДЛЕЖИТ ПАНИКАДИЛО ИЗ ААХЕНСКОЙ КАПЕЛЛЫ ${ }^{59}$. В ЭТОЙ СВЯЗИ ЗНАМЕНАТЕЛЬНО СВИДЕТЕЛЬСТВО ОЧЕВИДЦА О ЗОЛОТЫХ «ИЕРУСАЛИМАХ» В ЦЕРКВИ БОГОЛЮБОВА И УСПЕНСКОМ СОБОРЕ, Т. Е. В ДВУХ ПЕРВЫХ ХРАМАХ КНЯЗЯ АНДРЕЯ:

А ТРИЕ ЕРУСАЛИМЪ ВЕЛМИ ВЕЛИЦИИ, ИЖЕ ОТ ЗЛАТА ЧИСТА, ОТ КАМЕНЬЯ МНОГОЦЕНЪНА УСТРОИ: И ВСИМИ ВИДЫ И УСТРОЕНЬЕМЪ ПОДОБНА БЫСТА УДИВЛЕНИЮ СОЛОМОНОВ СВЯТАЯ СВЯТЫХъ. ${ }^{60}$

ПО ПРЕДПОЛОЖЕНИЮ НЕКОТОРЫХ ИССЛЕДОВАТЕЛЕЙ, В СОСТАВЕ БОЛЬШОГО МОСКОВСКОГО СИОНА ДО НАС ДОШЛА ЧАСТЬ ОДНОГО ИЗ ЭТИХ «ВЕЛИКИХ» ИЕРУСАЛИМОВ РОМАНСКОЙ РАБОТЫ ${ }^{11}$ [ИЛЛ. 7]. В ОТЛИЧИЕ ОТ ДАЛЕКИХ РОМАНСКИХ ХРАМОВ, ЛИТУРГИЧЕСКИЕ ПРЕДМЕТЫ В ФОРМАХ ЦЕРКОВНЫХ ЗДАНИЙ ВОСПРИНИМАЛИСЬ КАК УБЕДИТЕЛЬНЫЕ ОБРАЗЦЫ, К ТОМУ ЖЕ КОНЦЕПТУАЛЬНО И ЯРКО ВОПЛОЩАВШИЕ ИЕРУСАЛИМСКУЮ ИДЕЮ.

ПРИМЕЧАТЕЛЬНО, ЧТО ВЛАДИМИРО-СУЗДАЛЬСКИЕ ИКОНОГРАФИЧЕСКИЕ ПРОГРАММЫ НЕ ИМЕЮТ ПРЯМЫХ АНАЛОГИЙ В МОНУМЕНТАЛЬНЫХ ДЕКОРАЦИЯХ РОМАНСКИХ ХРАМОВ, ХОТЯ И ВОПЛОЩАЮТ ТУ ЖЕ ВАЖНЕЙШУЮ ДЛЯ ЭПОХИ ТЕМУ ТЕОФАНИИ. СИМВОЛИЧЕСКИ НАИБОЛЕЕ БЛИЗКИЕ РЕШЕНИЯ ДАЕТ ЛИТУРГИЧЕСКАЯ УТВАРЬ, И В ПЕРВУЮ ОЧЕРЕДЬ РОМАНСКИЕ КАДИЛЬНИЦЫ. ИМЕННО ОНИ, ПО УЖЕ ЦИТИРОВАВШЕМУСЯ СВИДЕТЕЛЬСТВУ ТЕОФИЛА, ДЕЛАЛИСЬ «В ВИДЕ ГОРОДА, УВИДЕННОГО ПРОРОКОМ НА ГОРЕ», Т. Е. ИЗОБРАЖАЛИ НЕБЕСНЫЙ ИЕРУСАЛИМ КАК ГОРОД-ХРАМ ИЗ ВИДЕНИЯ ИЕЗЕКИИЛЯ (ИЕЗ. 40-48), ТЕКСТ КОТОРОГО (ИЕЗ. 41: 17-20), СОГЛАСНО НАШЕЙ ГИПОТЕЗЕ, ЛЕЖАЛ В ОСНОВЕ СИМВОЛИЧЕСКОГО ЗАМЫСЛА СКУЛЬПТУРНОЙ ДЕКОРАЦИИ ФАСАДОВ ВЛАДИМИРОСУЗДАЛЬСКИХ ХРАМОВ.

ЛИТУРГИЧЕСКИЕ СОСУДЫ МОГЛИ ПОВЛИЯТЬ НЕ ТОЛЬКО НА СИМВОЛИКУ, НО И НА ОСОБЫЙ ХУДОЖЕСТВЕННЫЙ ОБРАЗ ВЛАДИМИРО-СУЗДАЛЬСКИХ ХРАМОВ. СХОДСТВО ХРАМОВ С ДРАГОЦЕННЫМИ ЛИТУРГИЧЕСКИМИ СОСУДАМИ ПОДЧЕРКИВАЛО ОБИЛЬНОЕ ЗОЛОЧЕНИЕ ФАСАДОВ. СОГЛАСНО СВИДЕТЕЛЬСТВУ СОВРЕМЕННИКА, АНДРЕЙ Боголюьский 
И ВЪ БОГОЛЮБОМЪ, И ВЪ ВОЛОДИМЕРЕ ГОРОДЕ ВЕРХЪ БО ЗЛАТОМЪ УСТРОИ И КОМАРИ ПОЗОЛОТИ И ПОЯСЪ ЗЛАТОМЪ УСТРОИ, КАМЕНЬЕМ УСВЕТИ, И СТОЛПЪ ПОЗЛАТИ, И ИЗОВНУ ЦЕРКВИ И ПО КОМАРОМЪ ЖЕ ПОТКЫ ЗОЛОТЫ И КУБЪКЫ И ВЕТРИЛА ЗОЛОТОМЪ УСТРОЕНА ПОСТАВИ... ${ }^{62}$

\section{Видение Иезекииля в культуре XII века}

НОВАЯ ГИПОТЕЗА ПРОИСХОЖДЕНИЯ ИКОНОГРАФИИ ФАСАДОВ ВЛАДИМИРО-СУЗДАЛЬСКИХ ХРАМОВ, КОТОРАЯ ИЗЛОЖЕНА ВЫШЕ, В СВОЕ ВРЕМЯ ВЫЗВАЛА ЖИВОЕ ОБСУЖДЕНИЕ, ПОДДЕРЖКУ, РАВНО КАК И КРИТИКУ КОЛЛЕГ. Я ИСПОЛЬЗУЮ ПРЕДОСТАВИВШУЮСЯ ВОЗМОЖНОСТЬ, ЧТОБЫ ОТВЕТИТЬ НА ВОЗРАЖЕНИЯ НЕКОТОРЫХ КОЛЛЕГ И В ПЕРВУЮ ОЧЕРЕДЬ НА ПОДРОБНУЮ СТАТЬЮ А.М. ВЫСОЦКОГО, ЦЕЛИКОМ ПОСВЯЩЕННУЮ РАЗБОРУ НАШЕЙ ТЕОРИИ ${ }^{64}$. КАМНЕМ ПРЕТКНОВЕНИЯ СТАЛ ВОПРОС О ВОЗМОЖНОСТИ И ВЕРОЯТНОСТИ ИСПОЛЬЗОВАНИЯ ТЕКСТА ВИДЕНИЯ ИЕЗЕКИИЛЯ КАК ОДНОГО ИЗ ГЛАВНЫХ ИСТОЧНИКОВ СИМВОЛИКИ СКУЛЬПТУРНОЙ ДЕКОРАЦИИ РУССКИХ ХРАМОВ ХІІ ВЕКА. ПЕРВООЧЕРЕДНОЕ ЗНАЧЕНИЕ ИМЕЕТ ИЗВЕСТНОСТЬ САМОГО ТЕКСТА В ПРАВОСЛАВНОМ МИРЕ И КОНКРЕТНЕЕ, В КУЛЬТУРЕ ДОМОНГОЛЬСКОЙ РУСИ. МЫ МОЖЕМ БЫТЬ УВЕРЕНЫ В ТОМ, ЧТО ОПИСАНИЕ ХРАМА ИЗ ВИДЕНИЯ ИЕЗЕКИИЛЯ БЫЛО ИЗВЕСТНО ПРАКТИЧЕСКИ КАЖДОМУ ОБРАЗОВАННОМУ ЧЕЛОВЕКУ. В ВИЗАНТИИ ШИРОКОЕ РАСПРОСТРАНЕНИЕ ИМЕЛА КНИГА ПРОРОКОВ С ТОЛКОВАНИЯМИ, ГДЕ ТЕКСТ КАЖДОГО ПРОРОКА ПРЕДВАРЯЛСЯ ТОЛКОВАНИЕМ ФЕОДОРИТА КИРСКОГО И ЗАКАНЧИВАЛСЯ ЖИТИЕМ ИЕЗЕКИИЛЯ, НАПИСАННЫМ ДОРОФЕЕМ ИЛИ ЕПИФАНИЕМ КИПРСКИМ. НЕ ВСЕ ПРОРОКИ ВОШЛИ В КНИГУ, НЕКОТОРЫЕ ПРЕДСТАВЛЕНЫ ЛИШЬ В ВЫДЕРЖКАХ, НО ЭТО НЕ ОТНОСИТСЯ К КНИГЕ 
ИЕЗЕКИИЛЯ, ПРИВЕДЕННОЙ ПОЛНОСТЬЮ. КНИГА ПРОРОКОВ С ТОЛКОВАНИЯМИ БЫЛА ПЕРЕВЕДЕНА И ХОРОШО ИЗВЕСТНА НА РУСИ ЕЩЕ В ХІ ВЕКЕ. СОГЛАСНО ДРЕВНЕЙШЕМУ ИЗ ДОШЕДШИХ ДО НАС РУССКИХ КОЛОФОНОВ КНИГА ПРОРОКОВ БЫЛА ПЕРЕПИСАНА В 1047 Г. ДЛЯ НОВГОРОДСКОГО КНЯЗЯ ВЛАДИМИРА ЯРОСЛАВИЧА ПОПОМ УПЫРЕМ ЛИХИМ, ОДНАКО ОПИСАНИЕ НЕБЕСНОГО ХРАМА В КНИГЕ НИКАК СПЕЦИАЛЬНО НЕ ВЫДЕЛЕНО. ТОЛКОВАНИЕ ФЕОДОРИТА КИРСКОГО (V В.) ПРОСТО ПЕРЕСКАЗЫВАЕТ ТЕКСТ ИЕЗЕКИИЛЯ.

ПРИ ЭТОМ ЕСТЬ ОСНОВАНИЕ ПОЛАГАТЬ, ЧТО В ПРАВОСЛАВНОЙ ТРАДИЦИИ ОПИСАНИЕ ИЕЗЕКИИЛЯ ПРИНАДЛЕЖИТ К САМЫМ ИЗВЕСТНЫМ И В БОГОСЛОВСКОМ ОТНОШЕНИИ НАИБОЛЕЕ ПРИМЕЧАТЕЛЬНЫМ РАЗДЕЛАМ ТЕКСТА ИЕЗЕКИИЛЯ. ЭТО СВЯЗАНО С ПОЛЕМИКОЙ ВОКРУГ ИКОНОПОЧИТАНИЯ. СВ. ЛЕОНТИЙ НЕАПОЛЬСКИЙ В VII В. ПРИВЕЛ ЭТО ОПИСАНИЕ В КАЧЕСТВЕ ВАЖНЕЙШЕГО АРГУМЕНТА В ЗАЩИТУ ИКОН. СВ. ЛЕОНТИЯ И ЕГО ПАРАФРАЗ ОПИСАНИЯ ИЕЗЕКИИЛЯ ЦИТИРУЕТ СВ. ИОАНН ДАМАСКИН В ТРЕХ ЗАЩИТИТЕЛЬНЫХ СЛОВАХ ПРОТИВ ПОРИЦАЮЩИХ СВЯТЫЕ ИКОНЫ. НЕСКОЛЬКО ПОЗДНЕЕ В 787 Г. ТОТ ЖЕ ТЕКСТ ПРОИЗНОСИТСЯ НА СЕДЬМОМ ВСЕЛЕНСКОМ СОБОРЕ В ЧИСЛЕ ОСНОВНЫХ ДОКАЗАТЕЛЬСТВ В ПОЛЬЗУ СВЯТОСТИ И ДРЕВНОСТИ ИКОНОПОЧИТАНИЯ ${ }^{65}$. ДЕКОРАЦИЯ НЕБЕСНОГО ХРАМА, ЯВЛЕННОГО ПРОРОКУ ИЕЗЕКИИЛЮ САМИМ БОГОМ, ВОСПРИНИМАЛАСЬ В ПРАВОСЛАВНОЙ ТРАДИЦИИ КАК ОДИН ИЗ НАИБОЛЕЕ АВТОРИТЕТНЫХ ИКОННЫХ ОБРАЗОВ. МАЛО СОМНЕНИЙ, ЧТО АНДРЕЙ БОГОЛЮБСКИЙ, БОГОСЛОВ И КНИЖНИК, БЫЛ ЗНАКОМ С ТЕКСТОМ ИЕЗЕКИИЛЯ И ЕГО БОГОСЛОВСКИМ ТОЛКОВАНИЕМ В ТРУДАХ ИКОНОПОЧИТАТЕЛЕЙ.

РИ ЭТОМ НАМ НИЧЕГО НЕ ИЗВЕСТНО О СПЕЦИАЛЬНОМ ИНТЕРЕСЕ К ТЕКСТУ ИЕЗЕКИИЛЯ В ВИЗАНТИЙСКОЙ И РУССКОЙ КУЛЬТУРЕ ХІІ ВЕКА. ОДНАКО ИМЕННО В ЭТО СТОЛЕТИЕ ОН ПРИОБРЕЛ ИСКЛЮЧИТЕЛЬНОЕ ЗНАЧЕНИЕ В ЛАТИНСКОЙ ТРАДИЦИИ. В СЕРЕДИНЕ СТОЛЕТИЯ ВЕДУЩИЕ БОГОСЛОВЫ ЭПОХИ - РИШАР И АНДРЕЙ ИЗ ПАРИЖСКОГО АББАТСТВА СЕН ВИКТОР - СОЗДАЮТ ДВА НОВЫХ ТРАКТАТА КОММЕНТИРУЮЩИХ ВИДЕНИЕ ИЕЗЕКИИЛЯ ${ }^{6}$. В ИСТОЛКОВАНИИ ДЕКОРАЦИИ НЕБЕСНОГО ХРАМА (ИЕЗ.41,17-20) БОГОСЛОВЫ ХІІ ВЕКА СЛЕДУЮТ ОСНОВОПОЛАГАЮЩЕМУ КОММЕНТАРИЮ БЛАЖЕННОГО ИЕРОНИМА НАЧАЛА $\mathrm{V}$ BEКA ${ }^{67}$.

СВ. ИЕРОНИМ ПОДЧЕРКИВАЕТ МЫСЛЬ О «РАЗУМЕ И МЕРЕ» В ДЕКОРАЦИИ СВЯТАЯ СВЯТЫХ, СОЗДАННОЙ САМИМ БОГОМ. ОН ОТМЕЧАЕТ, ЧТО МАСТЕРСТВО ИСПОЛНЕНИЯ БЫЛО ТАКИМ, «ЧТО ИЗОБРАЖЕНИЯ КАЗАЛИСЬ НЕ ВЫРЕЗАННЫМИ, А СДЕЛАННЫМИ ОТДЕЛЬНО И ПРИКРЕПЛЕННЫМИ». СОГЛАСНО ЭТОМУ ИСТОЛКОВАНИЮ, ХЕРУВИМЫ НА СТЕНАХ СИМВОЛИЗИРУЮТ МНОГОЗНАНИЕ, ПАЛЬМЫ ЯВЛЯЮТСЯ ЗНАКОМ ПОБЕДЫ. КАЖДЫЙ ХЕРУВИМ, РАСПОЛОЖЕННЫЙ МЕЖДУ ДВУХ ПАЛЬМ, ИМЕЛ ДВА ЛИЦА. ЛИЦО ЧЕЛОВЕЧЕСКОЙ ИСТОЛКОВЫВАЛОСЬ КАК ОБРАЗ РАЗУМА, А ЛИЦО ЛЬВИНОЕ КАК ОБРАЗ ГНЕВА, «ПРИДАЮЩЕГО СИЛЫ ДУШЕ СРАЖАЮЩЕГОСЯ». СОГЛАСНО СВ. ИЕРОНИМУ ИМЕННО ЭТИ КАЧЕСТВА (РАЗУМ И ДУШЕВНАЯ СТОЙКОСТЬ) НУЖНЕЕ ВСЕГО ПЕРЕД ВХОДОМ В СВЯТИЛИЩЕ ХРАМА, КОТОРОЕ СТАНОВИТСЯ ДОСТУПНЫМ ПОСЛЕ ТОГО, КАК ПРИ ПОМОЩИ НОВОГО МНОГО ЗНАНИЯ (ХЕРУВИМЫ) ДОСТИГАЕТСЯ ПОБЕДА НАД ВРАГОМ (ПАЛЬМЫ). КОММЕНТАРИЙ СВ. ИЕРОНИМА АКЦЕНТИРУЕТ ВЫСОКИЙ СМЫСЛ СОЗДАННОЙ САМИМ БОГОМ ПРОГРАММЫ ИЗОБРАЖЕНИЙ НА СТЕНАХ «СВЯТАЯ СВЯТЫХ». ПРИ ЭТОМ САМ ТЕКСТ ВОСПРИНИМАЕТСЯ КАК ОЧЕВИДНЫЙ ОБРАЗЕЦ ДЛЯ ПОДРАЖАНИЯ.

ТЕКСТ КОММЕНТАРИЯ ИЕРОНИМА С ОГРОМНОЙ ВЕРОЯТНОСТЬЮ БЫЛ ИЗВЕСТЕН РОМАНСКИМ ХУДОЖНИКАМ. ПРИМЕЧАТЕЛЬНО, ЧТО ОН БЫЛ ВОСПРИЗВЕДЕН (В ПЕРЕСКАЗЕ ХІ В.) В ИМЕВШЕЙ ШИРОЧАЙШЕЕ РАСПРОСТРАНЕНИЕ ЛАТИНСКОЙ БИБЛИИ С 
КОММЕНТАРИЯМИ (Biblia Latina cum glossa ordinaria), КОТОРАЯ С СЕРЕДИНЫ ХІІ В. СТАНОВИТСЯ НА ЗАПАДЕ ЕДВА ЛИ НЕ ГЛАВНЫМ ИСТОЧНИКОМ БИБЛЕЙСКИХ ЗНАНИЙ ${ }^{6}$.

В ИНТЕРЕСУЮЩЕМ НАС КОНТЕКСТЕ ВАЖНО, ЧТО В СЕРЕДИНЕ ХІІ В. ПОЯВЛЯЕТСЯ ЖЕЛАНИЕ ПРЕДСТАВИТЬ НЕБЕСНЫЙ ХРАМ ИЕЗЕКИИЛЯ В ГРАФИЧЕСКИХ ОБРАЗАХ. ВОЗНИКАЕТ ОСОБЫЙ ТИП ИЛЛЮСТРИРОВАННОЙ РУКОПИСИ, А ИМЕННО «КОММЕНТАРИЙ НА ВИДЕНИЕ ИЕЗЕКИИЛЯ» РИШАРА СЕН ВИКТОРСКОГО, КОТОРЫЙ СОПРОВОЖДАЛИ РИСУНКИ-ИЛЛЮСТРАЦИИ, ИЗОБРАЖАЮЩИЕ АРХИТЕКТУРНЫЕ СТРУКТУРЫ ХРАМА ИЕЗЕКИИЛЯ. СОХРАНИЛОСЬ ЗНАЧИТЕЛЬНОЕ ЧИСЛО СПИСКОВ: ИССЛЕДОВАТЕЛЮ ЭТОЙ РУКОПИСИ ВАЛЬТЕРУ КАНУ ИЗВЕСТНО 13 СОХРАНИВШИХСЯ СПИСКОВ СО ВТОРОЙ ПОЛОВИНЫ ХІІ В. - ПО КОНЕЦ ХІІІ ВЕКА БОЛЬШЕ, ПОСКОЛЬКУ МНЕ ПОСЧАСТЛИВИЛОСЬ ДЕРЖАТЬ В РУКАХ НЕИЗВЕСТНЫЙ ПРОФЕССОРУ КАНУ СПИСОК НАЧАЛА ХІІІ В., ХРАНЯЩИЙСЯ В ОТДЕЛЕ РУКОПИСЕЙ Firestone Library В ПРИНСТОНСКОМ УНИВЕРСИТЕТЕ.

РИШАР СЕН ВИКТОРСКИЙ КОММЕНТИРУЕТ ЛИШЬ ПЕРВУЮ И ВОСЕМЬ ПОСЛЕДНИХ ГЛАВ ИЗ 48 ИЗВЕСТНЫХ В КНИГЕ ИЕЗЕКИИЛЯ. ТО ЕСТЬ ПЕРВУЮ ТЕОФАНИЮ НА РЕКЕ ХОВАР С ВИДЕНИЕМ «ПОДОБИЯ ЧЕТЫРЕХ ЖИВОТНЫХ» И ЗАКЛЮЧИТЕЛЬНОЕ ЯВЛЕНИЕ ГОРОДАХРАМА, «ПОКАЗАННОГО ПРОРОКУ НА ГОРЕ». РИСУНКИ, ВКЛЮЧЕННЫЕ В ТЕКСТ КОММЕНТАРИЯ, НАЧИНАЮТСЯ С ОБЩЕГО ПЛАНА ХРАМОВОГО КОМПЛЕКСА И ПРОДОЛЖАЮТСЯ В ИЗОБРАЖЕНИЯХ ОТДЕЛЬНЫХ АРХИТЕКТУРНЫХ СООРУЖЕНИЙ [ИЛЛ. 8]. ДЕТАЛИЗИРОВАННЫЕ РИСУНКИ, ИПОЛНЕННЫЕ В ДВА ЦВЕТА (КРАСНЫЙ И ЖЕЛТЫЙ) И СОПРОВОЖДАЕМЫЕ ПОЯСНЯЮЩИМИ НАДПИСЯМИ, НАПОМИНАЮТ ФУНКЦИОНАЛЬНЫЕ ДИАГРАММЫ, КОТОРЫЕ МОГЛИ БЫТЬ ПОВТОРЕНЫ ЛЮБЫМ КВАЛИФИЦИРОВАННЫМ ПИСЦОМ. ИХ ПОДЧЕРКНУТО ПРИКЛАДНОЙ ХАРАКТЕР ПОДЧАС ЗАСТАВЛЯЕТ ЗАБЫТЬ, ЧТО РЕЧЬ ИДЕТ ОБ ОБРАЗЕ НЕБЕСНОГО ХРАМА.

ВЛИЯНИЕ ЭТИХ ИЛЛЮСТРАЦИЙ МОЖЕТ БЫТЬ ОТМЕЧЕНО В РОМАНСКОМ ЗОДЧЕСТВЕ ХІІ В. РЕЧЬ, В ПЕРВУЮ ОЧЕРЕДЬ, ИДЕТ О МОТИВЕ ПОВТОРЯЮЩИХСЯ АРКАД НА ФАСАДАХ, НЕ ИМЕЮЩИХ НИКАКОГО ФУНКЦИОНАЛЬНОГО СМЫСЛА ${ }^{70}$. ВЫРАЗИТЕЛЬНЫЙ ПРИМЕР ИСПОЛЬЗОВАНИЯ ДАННОГО МОТИВА НАХОДИМ В ВЛАДИМИРО-СУЗДАЛЬСКОЙ АРХИТЕКТУРЕ ХІІ В. - ДЕКОРАЦИИ ФАСАДОВ В КНЯЖЕСКОЙ РЕЗИДЕНЦИИ В БОГОЛЮБОВО, ПОСТРОЕННОЙ, ПО ВСЕЙ ВИДИМОСТИ, МАСТЕРАМИ ФРИДРИХА БАРБАРОССЫ, СТРЕМЯЩЕМСЯ ВОПЛОТИТЬ В ДВОРЦОВО-ХРАМОВОМ КОМПЛЕКСЕ ИДЕЮ НЕБЕСНОГО ГРАДА. РОМАНСКИЕ МАСТЕРА, РАБОТАВШИЕ ДЛЯ АНДРЕЯ БОГОЛЮБСКОГО, МОГЛИ ЗНАТЬ ИЛЛЮСТРИРОВАННЫЙ КОММЕНТАРИЙ РИШАРА СЕН ВИКТОРСКОГО. В ЛЮБОМ СЛУЧАЕ, ОНИ ПРИНАДЛЕЖАЛИ К КУЛЬТУРЕ, ИМЕННО В ТРЕТЬЕЙ ЧЕТВЕРТИ ХІІ В. СОСРЕДОТОЧЕНО РАЗМЫШЛЯЮЩЕЙ НАД СИМВОЛИЧЕСКИМИ СМЫСЛАМИ ВИДЕНИЯ ИЕЗЕКИИЛЯ И ВОЗМОЖНОСТЬЮ ИХ ВИЗУАЛЬНОГО ВОПЛОЩЕНИЯ.

ОЦЕНИВ ВАЖНОСТЬ ТЕКСТА В КУЛЬТУРЕ ХІІ ВЕКА И АКТУАЛЬНОСТЬ ЕГО ИСПОЛЬЗОВАНИЯ ПРИ СОЗДАНИИ ХРАМОВОЙ ДЕКОРАЦИИ, НЕОБХОДИМО ОТВЕТИТЬ НА ЕЩЕ НЕ ПРОЯСНЕННЫЙ ВОПРОС. КАК СВЯЗАН С ВИДЕНИЕМ ИЕЗЕКИИЛЯ ЦЕНТРАЛЬНЫЙ ОБРАЗ ВЛАДИМИРСКИХ ФАСАДОВ - ЦАРЬ ДАВИД, ВОССЕДАЮЩИЙ НА ТРОНЕ. КАК БЫЛО ПОКАЗАНО РАНЕЕ, ДАВИД В ДАННОМ СИМВОЛИЧЕСКОМ КОНТЕКСТЕ ЯВЛЯЕТСЯ ПРООБРАЗОМ ХРИСТА В ПОСЛЕДНЕЙ ТЕОФАНИИ. ИНТЕРЕСУЮЩИЙ НАС АСПЕКТ ПРОЯСНЯЕТ ОДНА ДЕТАЛЬ В УЖЕ РАССМОТРЕННОЙ ИКОНОГРАФИЯ ФРОНТИСПИСА ВИЗАНТИЙСКОЙ ПСАЛТЫРИ 1059 Г. ИЗ ВАТИКАНСКОЙ БИБЛИОТЕКИ (Vat. Bibl. Cod. gr. 752, fol. 18v) ${ }^{71}$. НАД СТОЯЩИМ ДАВИДОМ В ИМПЕРАТОРСКИХ ОДЕЯНИЯХ ПОКАЗАН ХРИСТОС НА ТРОНЕ, 
БЛАГОСЛОВЛЯЮЩИЙ ОТСТАВЛЕННОЙ ПРАВОЙ РУКОЙ. ДЛЯ НАС НАИБОЛЕЕ ИНТЕРЕСНО ИЗОБРАЖЕНИЕ ПРОРОКА С КНИГОЙ, ВОЗМОЖНО ИЕЗЕКИИЛЯ, СЛЕВА И НЕСКОЛЬКО ВЫШЕ СТОЯЩЕГО ДАВИДА. ДЕКЛАРАТИВНОЕ СОПОСТАВЛЕНИЕ ХРИСТА И ДАВИДА ЯСНО УВЯЗАНО С ПРОРОЧЕСКИМИ ВИДЕНИЯМИ. НЕСОМНЕННО, САМЫМ ВАЖНЫМ ИЗ ЭТИХ ВИДЕНИЙ БЫЛ ТЕКСТ ПЕРВОЙ ГЛАВЫ ИЗ КНИГИ ИЕЗЕКИИЛЯ, ОПИСЫВАЮЩЕЙ ТЕОФАНИЮ С ПОДОБИЯМИ ЖИВОТНЫХ НА РЕКЕ ХОВАР.

ПРИМЕЧАТЕЛЬНО, ЧТО В ХРИСТИАНСКОЙ ЭКЗЕГЕЗЕ ВИДЕНИЯ ИЕЗЕКИИЛЯ ИЗ ПЕРВОЙ ГЛАВЫ И ОПИСАНИЕ ХРАМА В ПОСЛЕДНИХ НЕРЕДКО ОБЪЕДИНЯЛИСЬ В ОДНО СИМВОЛИЧЕСКОЕ ЦЕЛОЕ. ХАРАКТЕРНЫЙ ПРИМЕР НАХОДИМ В КОММЕНТАРИИ РИШАРА СЕН ВИКТОРССКОГО. ВО МНОГИХ ТОЛКОВАНИЯХ УКАЗЫВАЕТСЯ, ЧТО ОБРАЗЫ «ХЕРУВИМОВ, ЛЬВОВ, ПАЛЬМ И ЛЮДЕЙ» ИЗ ДЕКОРАЦИИ НЕБЕСНОГО ХРАМА ВОСХОДЯТ К ВИДЕНИЮ «ПОДОБИЙ ЖИВОТНЫХ» НА РЕКЕ ХОВАР. НА РЕДКОЙ ИЛЛЮСТРАЦИИ ИЗ БИБЛИИ РИПОЛА ХІ В. ДВА ВИДЕНИЯ ПРЕДСТАВЛЕНЫ ВМЕСТЕ В ОДНОЙ СИМВОЛИЧЕСКОЙ СЦЕНЕ. ОПИСАНИЕ ДЕКОРАЦИИ НЕБЕСНОГО ХРАМА СОДЕРЖАЛО В СЕБЕ АЛЛЮЗИЮ НА «ВЕЛИКУЮ ТЕОФАНИЮ» ПЕРВОЙ ГЛАВЫ ИЕЗЕКИИЛЯ. ЗНАЧЕНИЕ ЭТОЙ ТЕОФАНИИ ТРУДНО ПЕРЕОЦЕНИТЬ. ВИДЕНИЕ С ПОДОБИЯМИ ЖИВОТНЫХ, ИСТОЛКОВАННЫМИ КАК СИМВОЛЫ ЕВАНГЕЛИСТОВ, ВСТРЕЧАЮТСЯ В ДРЕВНЕЙШИХ ПРОГРАММАХ АЛТАРНЫХ АПСИД, НАПРИМЕР, В РОСПИСЯХ БАУИТА VI В. ${ }^{72}$ УЖЕ ДРЕВНЕЙШИЕ ИЗОБРАЖЕНИЯ УКАЗЫВАЮТ НА СВЯЗЬ ТЕОФАНИИ И ВТОРОГО ПРИШЕСТВИЯ. ТАК МОТИВЫ ВИДЕНИЯ ИЕЗЕКИИЛЯ ВКЛЮЧАЮТСЯ В МИНИАТЮРУ СО СЦЕНОЙ «ВОЗНЕСЕНИЯ» ИЗ ЕВАНГЕЛИЯ РАББУЛЫ 586 Г. ХРИСТОС В МАНДОРЛЕ, ОПИРАЮЩЕЙСЯ НА МНОГООЧИТЫЕ КРЫЛЬЯ, СИМВОЛЫ ЕВАНГЕЛИСТОВ И ОГНЕННЫЕ КОЛЕСА, ПОКАЗАН ВОЗНОСЯЩЕМСЯ И ОДНОВРЕМЕННО КАК БЫ СХОДЯЩИМ С НЕБЕС. МЫСЛЬ О ВТОРОМ ПРИШЕСТВИИ, ЗАКЛЮЧЕННАЯ В САМОМ НОВОЗАВЕТНОМ ТЕКСТЕ (ДЕЯН. 1, 11), ПОДЧЕРКИВАЮТ ИЗОБРАЖЕНИЯ АНГЕЛОВ, В ПОКРОВЕННЫХ РУКАХ КОТОРЫХ ЗОЛОТЫЕ ВЕНЦЫ, ПРЕДНАЗНАЧЕННЫЕ ДЛЯ СВЯТЫХ ПРАВЕДНИКОВ В ДЕНЬ СТРАШНОГО СУДА. ВОЗМОЖНОСТЬ ТАКОЙ ИНТЕРПРЕТАЦИИ ЗАКЛЮЧЕНА В ТЕКСТЕ АПОКАЛИПСИСА (ОТК. 4, 6-9), ПЕРЕФРАЗИРУЮЩЕМ ВИДЕНИЕ ИЕЗЕКИИЛЯ С ВАЖНЕЙШИМ ДОБАВЛЕНИЕМ ТЕМЫ БОГОСЛУЖЕНИЯ ЧЕТЫРЕХ ЖИВОТНЫХ, КОТОРЫЕ «НИ ДНЕМ, НИ НОЧЬЮ НЕ ИМЕЮТ ПОКОЯ, ВЗЫВАЯ: СВЯТ, СВЯТ, СВЯТ ГОСПОДЬ БОГ ВСЕДЕРЖИТЕЛЬ, КОТОРЫЙ БЫЛ, ЕСТЬ И ГРЯДЕТ» (ОТк. 4, 8).

ЭТОМ БОГОСЛУЖЕНИИ УЧАСТВУЮТ И ДВАДЦАТЬ ЧЕТЫРЕ АПОКАЛИПТИЧЕСКИХ СТАРЦА, КОТОРЫЕ В ЗАПАДНОЙ ТРАДИЦИИ ЧАСТО ВКЛЮЧАЮТСЯ В ИЗОБРАЖЕНИЕ «ВИДЕНИЯ ИЕЗЕКИИЛЯ» (ЯРКИЙ ПРИМЕР МИНИАТЮРА ИЗ АПОКАЛИПСИСА СЕН СЕВЕРА СЕРЕДИНЫ XI B.).

ДЛЯ ПОНИМАНИЯ ИНТЕРЕСУЮЩЕГО НАС СИМВОЛИЧЕСКОГО ЗАМЫСЛА СУЩЕСТВЕННО, ЧТО ТЕОФАНИЯ ИЕЗЕКИИЛЯ ЯВЛЯЕТСЯ ЗДЕСЬ ЧАСТЬЮ ОБРАЗА НЕБЕСНОГО ИЕРУСАЛИМА, ГДЕ И ПРОИСХОДИТ БОГОСЛУЖЕНИЕ. ЗНАМЕНАТЕЛЬНО, ЧТО ТЕ ЖЕ АПОКАЛИПТИЧЕСКИЕ МОТИВЫ И ИЕРУСАЛИМСКИЙ КОНТЕКСТ ПРИСУТСТВУЮТ И В МОНУМЕНТАЛЬНЫХ «ТЕОФАНИЯХ» РОМАНСКИХ ПОРТАЛОВ. НАИБОЛЕЕ ИЗВЕСТНЫЕ ПРИМЕРЫ ХІІ В.: КОРОЛЕВСКИЙ ПОРТАЛ ШАРТРА, СКУЛЬПТУРНАЯ ДЕКОРАЦИЯ СОБОРА В МУАСАКЕ ИЛИ СЕН ТРОФИМ В АРЛЕ. В СОВРЕМЕННОЙ НАУЧНОЙ ЛИТЕРАТУРЕ ПО ИКОНОЛОГИИ РОМАНСКИХ ПОРТАЛОВ ВЫДЕЛЯЮТСЯ РАЗНЫЕ ТИПЫ ТЕОФАНИЙ (В ЧАСТНОСТИ ТЕОФАНИИ ПЕРВОГО ПРИШЕСТВИЯ, ОТ ВОПЛОЩЕНИЯ ДО КОНЦА ВРЕМЕН, ВТОРОГО ПРИШЕСТВИЯ И СОБСТВЕННО СТРАШНОГО СУДА). ОДНАКО ДЛЯ НАШИХ ЦЕЛЕЙ ЭТИ ДЕФИНИЦИИ НЕ СТОЛЬ ЗНАЧИМЫ. 
ГОРАЗДО ВАЖНЕЕ ДРУГОЕ: ТЕМА ТЕОФАНИИ, ПРИСУТСТВУЮЩАЯ НА ФАСАДАХ ВЛАДИМИРО-СУЗДАЛЬСКИХ ХРАМОВ, ЯВЛЯЕТСЯ ДОМИНИРУЮЩЕЙ В РОМАНСКОЙ СКУЛЬПТУРНОЙ ДЕКОРАЦИИ. ПРИ ЭТОМ ОНА ОСМЫСЛЯЕТСЯ В КОНТЕКСТЕ ВИДЕНИЯ ИЕЗЕКИИЛЯ И СИМВОЛИКИ НЕБЕСНОГО ИЕРУСАЛИМА, ЧТО ДОПОЛНИТЕЛЬНО ПОДТВЕРЖДАЕТ НАШЕ МНЕНИЕ ОБ ВОЗМОЖНОСТИ ИСПОЛЬЗОВАНИИ АВТОРАМИ ВЛАДИМИРСКИХ СКУЛЬПТУРНЫХ ИКОН ОПИСАНИЯ НЕБЕСНОГО ХРАМА ИЕЗЕКИИЛЯ В КАЧЕСТВЕ ГЛАВНОГО ИСТОЧНИКА.

\section{ANNEXES}

\section{Список иллюстраций}

1. ЮЖНЫЙ ФАСАД ЦЕРКВИ ПОКРОВА НА НЕРЛИ. ХІІ ВЕК

2. ЦЕНТРАЛЬНОЕ ПРЯСЛО ЮЖНОГО ФАСАДА ЦЕРКВИ ПОКРОВА НА НЕРЛИ. ХІІ ВЕК

3. ЦАРЬ ДАВИД НА ТРОНЕ. ЗАПАДНЫЙ ФАСАД ЦЕРКВИ ПОКРОВА НА НЕРЛИ. ХІІ ВЕК

4. ДМИТРИЕВСКИЙ СОБОР ВО ВЛАДИМИРЕ, ВИД НА ЗАПАДНЫЙ ФАСАД. ХІІ ВЕК

5. ЦАРЬ ДАВИД НА ТРОНЕ. РЕЛЬЕФЫ ЮЖНОГО ФАСАДА ДМИТРИЕВСКОГО СОБОРА ВО ВЛАДИМИРЕ. ХІІ ВЕК

6. КАДИЛЬНИЦА ГОЗБЕРТА. СОКРОВИЩНИЦА СОБОРА В ТРИРЕ. ХІ ВЕК

7. БОЛЬШОЙ МОСКОВСКИЙ ИЕРУСАЛИМ (СИОН). ОСНОВА - РОМАНСКАЯ РАБОТА ХІІ ВЕКА, ГЛАВКА - КОНЕЦ ХV ВЕКА. ОРУЖЕЙНАЯ ПАЛАТА МОСКОВСКОГО КРЕМЛЯ

8. ХРАМ ИЕЗЕКИИЛЯ. ИЛЛЮСТРАЦИЯ К КОММЕНТАРИЮ НА ВИДЕНИЕ ИЕЗЕКИИЛЯ РИШАРА СЕН ВИКТОРСКОГО. ХІІ ВЕК (Paris, Bibl. Nat., Lat. 14516, fol. 240) 
Fig. 1. Église de l'Intercession de la Vierge (Pokrov) sur la Nerle, XII ${ }^{\mathrm{e}}$ siècle, façade sud

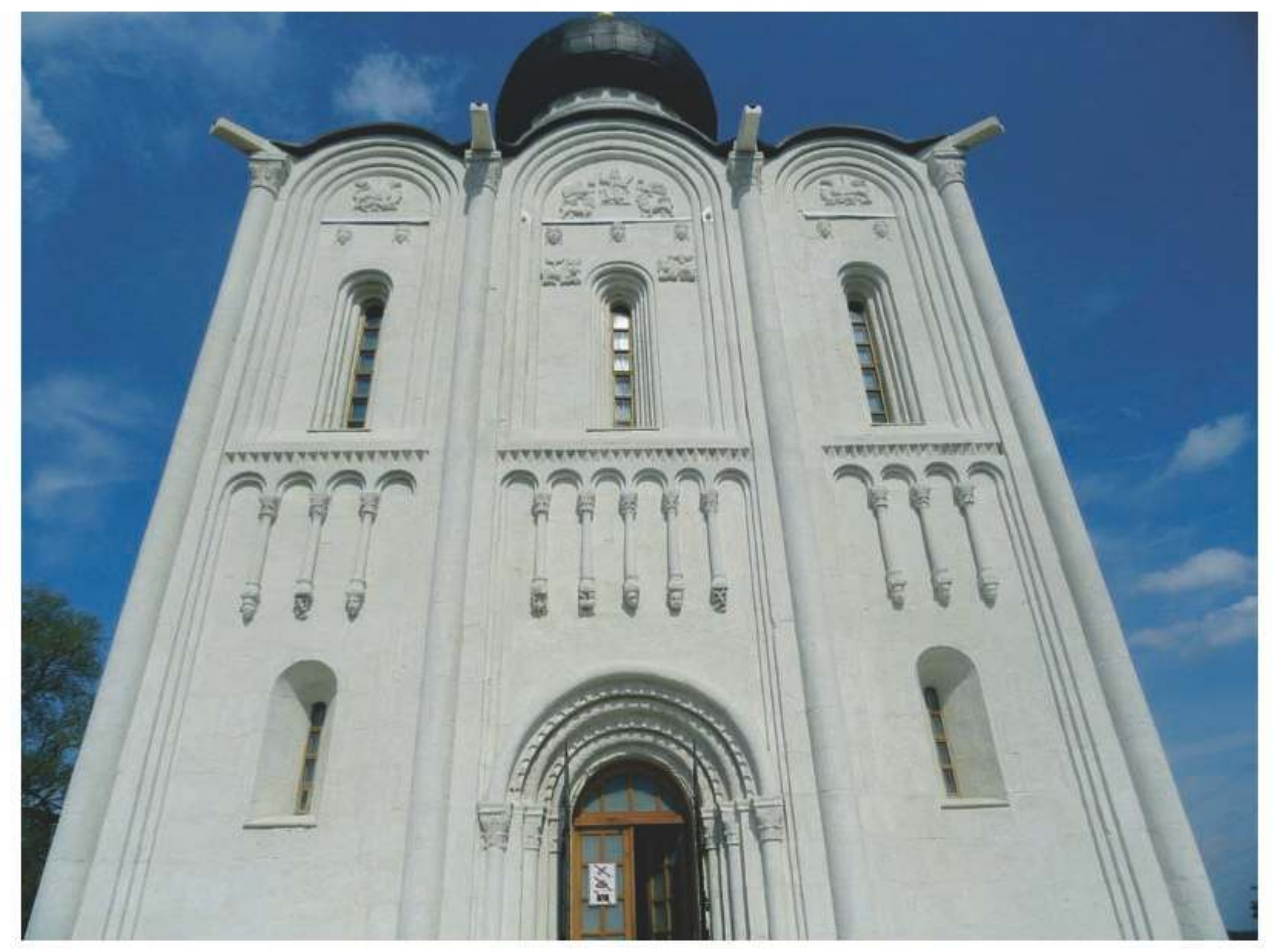

Fig. 2. Église de Pokrov sur la Nerle : Travée centrale de la façade sud, $X \|^{\mathrm{e}}$ siècle

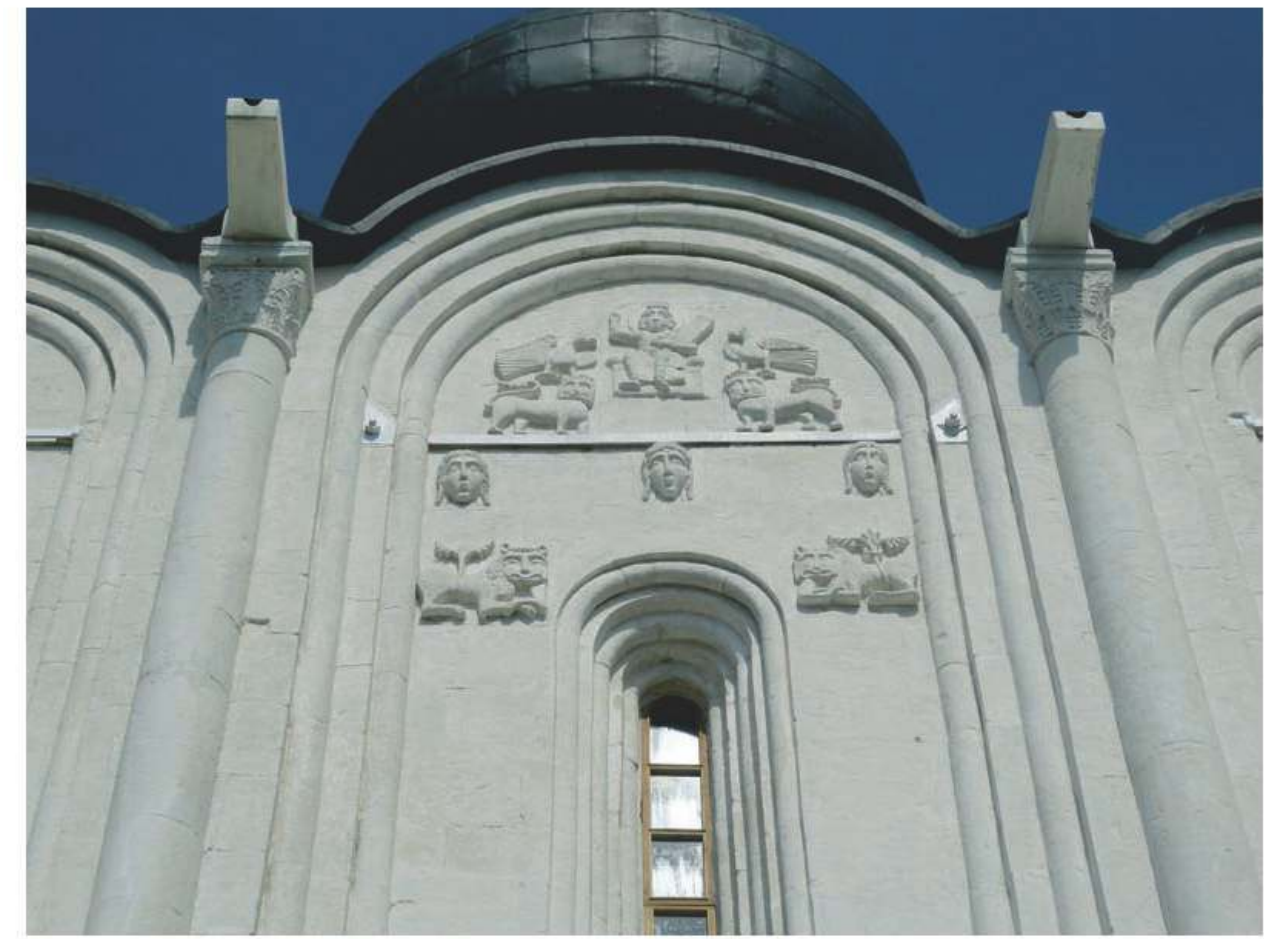


Fig. 3. Le roi David sur son trône. Façade ouest de l'Église de Pokrov sur la Nerle, XIIe siècle

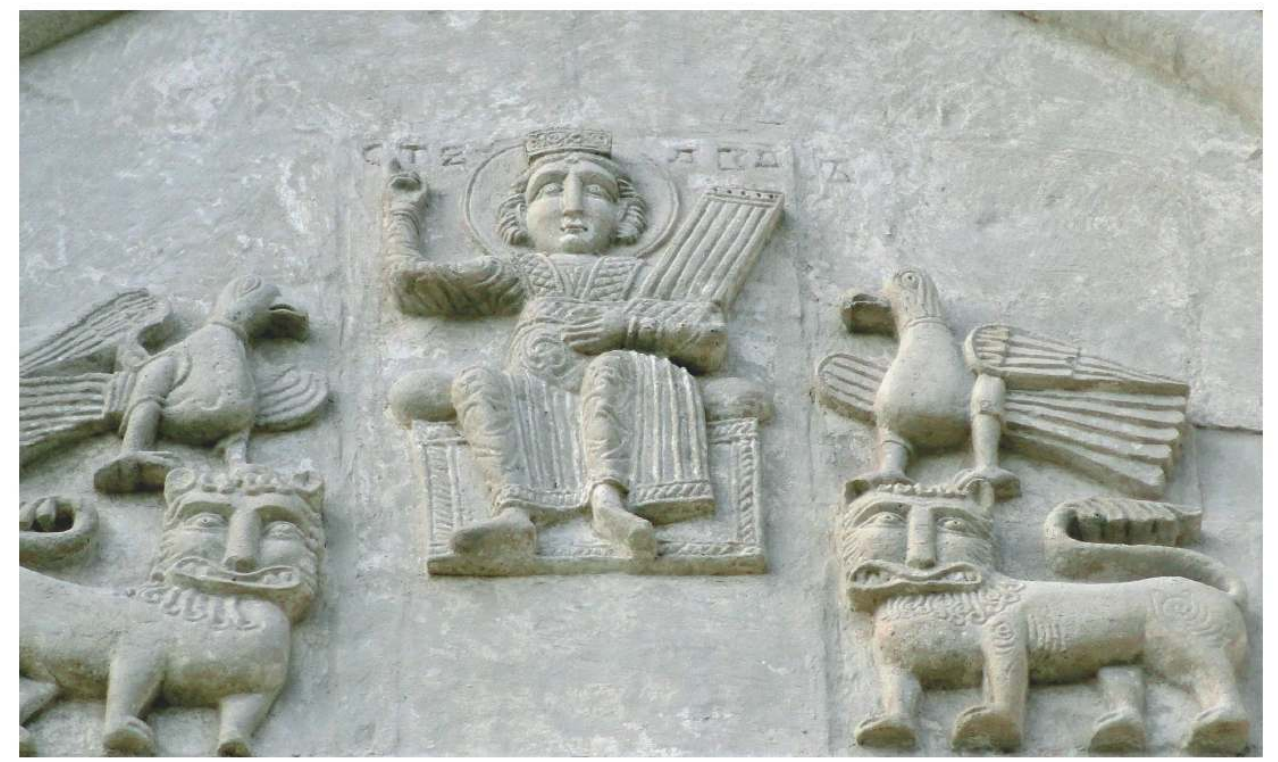

Fig. 4. Cathédrale Saint-Dimitri à Vladimir, vue sur la façade occidentale, $\mathrm{XII}$ siècle

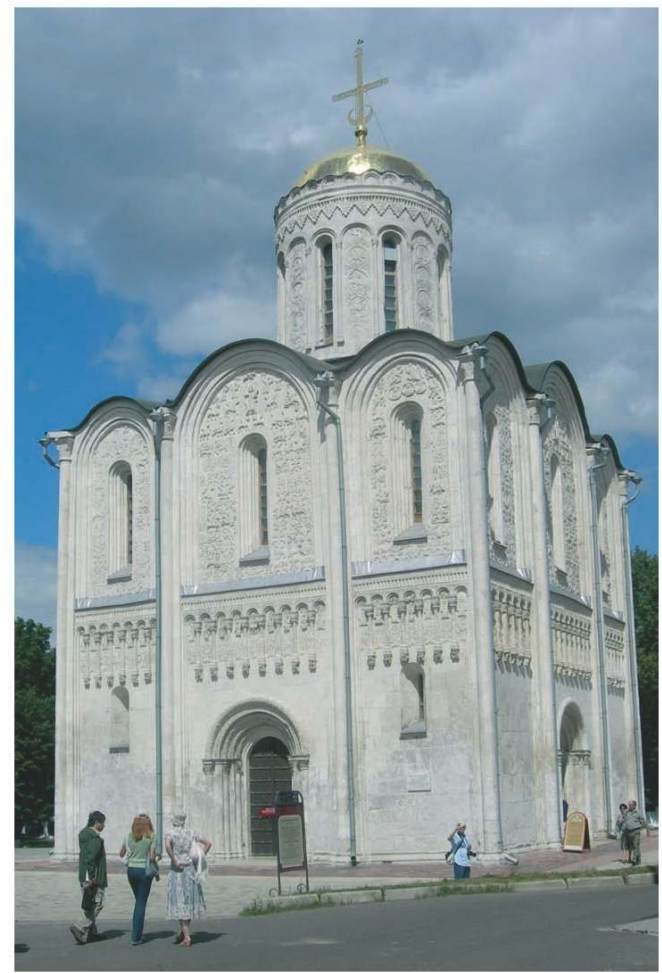


Fig. 5. Le roi David sur son trône. Cathédrale Saint-Dimitri à Vladimir, reliefs de la façade sud, xII siècle

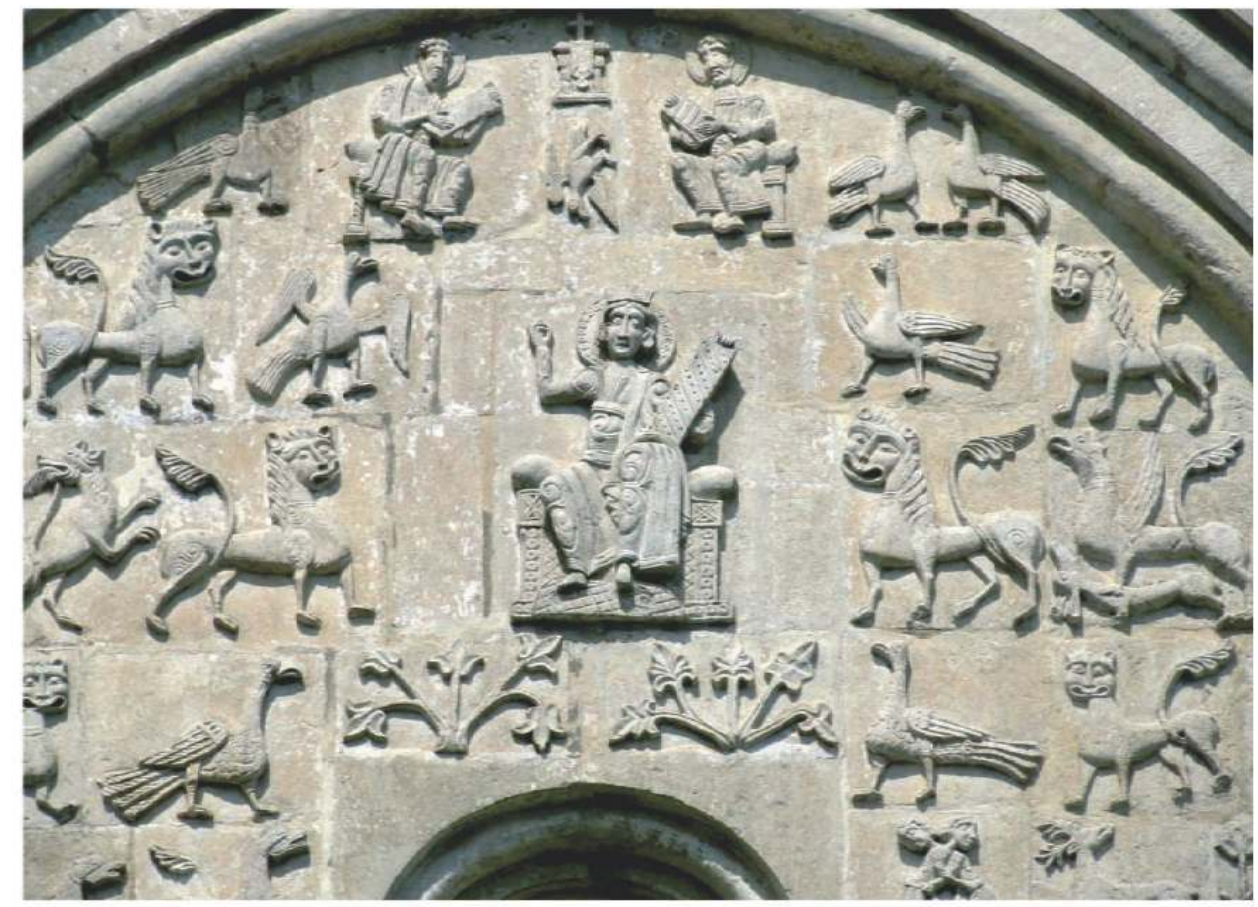

Fig. 6. Encensoir de Gozbert. Trésor de la cathédrale de Trèves, $\mathrm{XI}^{\mathrm{e}}$ siècle

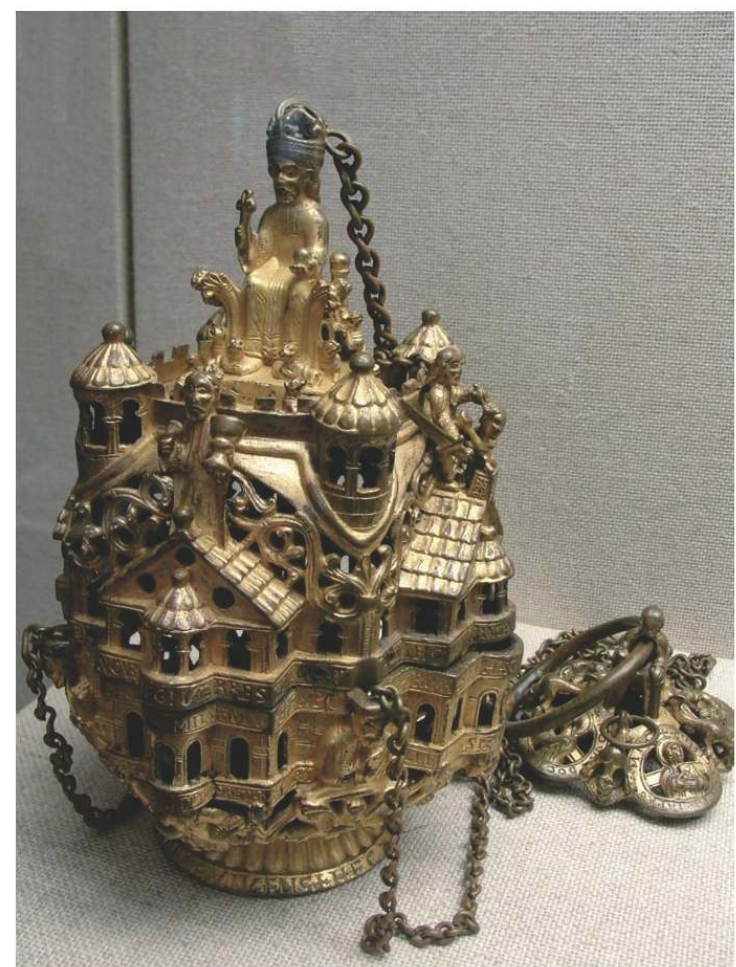


Fig. 7. Grande " Jérusalem » (ou "sainte-Sion ») de Moscou ( $x{ }^{\mathrm{e}}$ - fin du xve siècle). Palais des armures du Kremlin

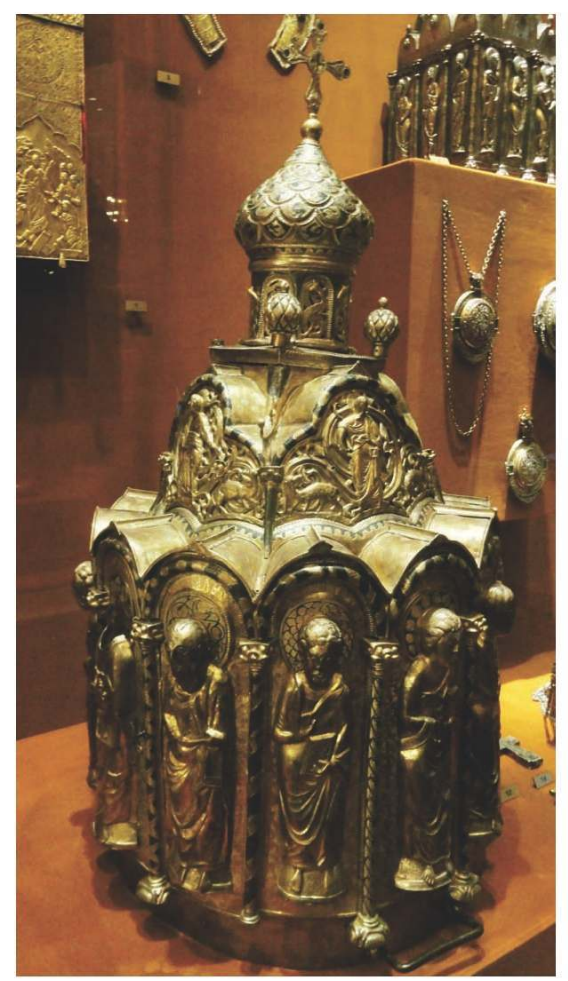

Fig. 8. Le temple d'Ézéchiel. Illustration du commentaire sur la Vision d'Ézéchiel par Richard de Saint-Victor, XII siècle (Paris, Bibl. Nat. Lat.14516, fol.240)

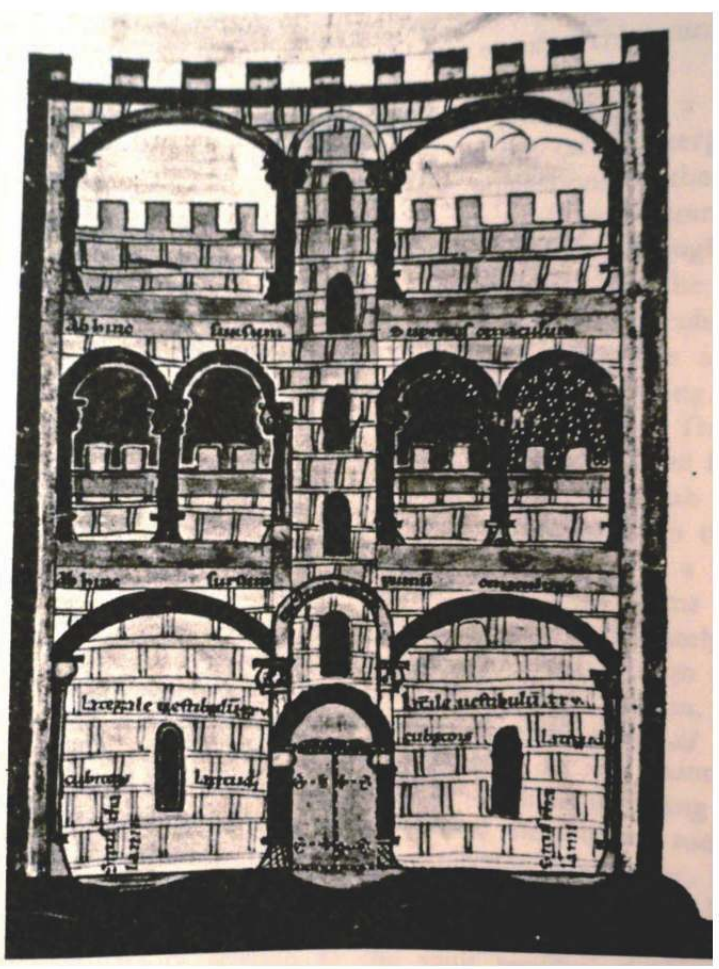




\section{NOTES}

1. В ДАННОЙ НАУЧНОЙ РАБОТЕ ИСПОЛЬЗОВАНЫ РЕЗУЛЬТАТЫ ПРОЕКТА «ВОСТОК И ЗАПАД ЕВРОПЫ В СРЕДНИЕ ВЕКА И РАННЕЕ НОВОЕ ВРЕМЯ: ОБЩЕЕ ИСТОРИКО-КУЛЬТУРНОЕ ПРОСТРАНСТВО, РЕГИОНАЛЬНОЕ СВОЕОБРАЗИЕ И ДИНАМИКА ВЗАИМОДЕЙСТВИЯ», ВЫПОЛНЕННОГО В РАМКАХ ПРОГРАММЫ ФУНДАМЕНТАЛЬНЫХ ИССЛЕДОВАНИЙ НИУ ВШЭ В 2013 годУ.

А.М. ЛИДОВ, «НОВЫЕ ИЕРУСАЛИМЫ. ПЕРЕСОЗДАНИЕ СВЯТОЙ ЗЕМЛИ КАК ПОРОЖДАЮЩАЯ МАТРИЦА ХРИСТИАНСКОЙ КУЛЬТУРЫ» in А.М. ЛИДОВ, РЕД.-СОСТ., НОВЫЕ ИЕРУСАЛИМЫ: ИЕРОТОПИЯ И ИКОНОГРАФИЯ САКРАЛЬНЫХ ПРОСТРАНСТВ, М., 2009, С. 5-10.

2. А.М. ЛИДОВ, ИЕРОТОПИЯ: ПРОСТРАНСТВЕННЫЕ ИКОНЫ И ОБРАЗЫ-ПАРАДИГМЫ В ВИЗАНТИЙСКОЙ КУЛЬТУРЕ, М., 2009.

3. К.К. АКЕНТЬЕВ, «МОЗАИКИ КИЕВСКОЙ СВ. СОФИИ И «СЛОВО» МИТРОПОЛИТА ИЛАРИОНА В ВИЗАНТИЙСКОМ ЛИТУРГИЧЕСКОМ КОНТЕКСТЕ», in К.К. АКЕНТЬЕВ, РЕД., ЛИТУРГИЯ, АРХИТЕКТУРА И ИСКУССТВО ВИЗАНТИЙСКОГО МИРА, СПБ., 1995, С. 75-94.

4. НАСТОЯЩАЯ СТАТЬЯ ЯВЛЯЕТСЯ ДОПОЛНЕННЫМ И ПЕРЕРАБОТАННЫМ ВАРИАНТОМ РАБОТЫ: А.М. ЛИДОВ, «О СИМВОЛИЧЕСКОМ ЗАМЫСЛЕ СКУЛЬПТУРНОЙ ДЕКОРАЦИИ ВЛАДИМИРО-СУЗДАЛЬСКИХ ХРАМОВ ХІІ-ХІІІ ВЕКОВ», ДРЕВНЕРУССКОЕ ИСКУССТВО. ВИЗАНТИЯ, БАЛКАНЫ, РУСЬ. ХІІІ ВЕК, М., 1996, С. 172-184. СКУЛЬПТУРНОЙ ДЕКОРАЦИИ ВЛАДИМИРО-СУЗДАЛЬСКИХ ХРАМОВ ПОСВЯЩЕНО БОЛЬШОЕ ЧИСЛО ИССЛЕДОВАНИЙ, СРЕДИ КОТОРЫХ ОСОБОЕ ЗНАЧЕНИЕ ИМЕЮТ СЛЕДУЮЩИЕ РАБОТЫ: А.А. БОБРИНСКИЙ, РЕЗНОЙ КАМЕНЬ В РОССИИ, М.. 1916, ВЫП. 1.; F.W. Halle, Die Bauplastik von Wladimir-Susdal: Russische Romanik, Berlin, 1929 (ДАЛЕЕ - Halle, 1929); Н.Н. ВОРОНИН, ЗОДЧЕСТВО СЕВЕРОВОСТОЧНОЙ РУСИ ХІІ-ХV ВЕКОВ, М.. 1961-1962, Т. 1-2. (ДАЛЕЕ - ВОРОНИН, 1961-1962); Г.К. ВАГНЕР, СКУЛЬПТУРА ДРЕВНЕЙ РУСИ: ВЛАДИМИР, БОГОЛЮБОВО. ХІІ ВЕК. М., 1969 (ДАЛЕЕ ВАГНЕР, 1969). В ПОСЛЕДНЕЙ РАБОТЕ - ИСТОРИОГРАФИЧЕСКИЙ ОБЗОР ВСЕХ СУЩЕСТВОВАВШИХ К МОМЕНТУ ИЗДАНИЯ КНИГИ МНЕНИЙ (С. 7-44). СРЕДИ ПУБЛИКАЦИЙ, ВЫШЕДШИХ ПОСЛЕ НАШЕЙ СТАТЬИ, ОТМЕТИМ: Г.В.ПОПОВ, «ДЕКОРАЦИЯ ФАСАДОВ ДМИТРИЕВСКОГО СОБОРА И КУЛЬТУРА ВЛАДИМИРСКОГО КНЯЖЕСТВА НА РУБЕЖЕ ХІІ-ХIII ВВ.», ДМИТРИЕВСКИЙ СОБОР ВО ВЛАДИМИРЕ. К 800-ЛЕТИЮ СОЗДАНИЯ. М., 1997, С. 42-59; С.М. НОВАКОВСКАЯ-БУХМАН, «ЦАРЬ ДАВИД В РЕЛЬЕФАХ ДМИТРИЕВСКОГО СОБОРА ВО ВЛАДИМИРЕ», ДРЕВНЕРУССКОЕ ИСКУССТВО: ВИЗАНТИЯ, РУСЬ, ЗАПАДНАЯ ЕВРОПА: ИСКУССТВО И КУЛЬТУРА, СПБ., 2002, С. 172-186; ОНА ЖЕ, «ОБ ИСТОКАХ ИКОНОГРАФИИ И СИМВОЛИКИ ОБРАЗА ЦАРЯ ДАВИДА НА ФАСАДАХ ВЛАДИМИРСКИХ ХРАМОВ ХІІ ВЕКА», ВИЗАНТИЯ В КОНТЕКСТЕ МИРОВОЙ КУЛЬТУРЫ: К СТОЛЕТИЮ А.В.БАНК, СПБ., 2008, С. 503-517; М.С. ГЛАДКАЯ, РЕЛЬЕФЫ ДМИТРИЕВСКОГО СОБОРА ВО ВЛАДИМИРЕ: ОПЫТ КОМПЛЕКСНОГО ИССЛЕДОВАНИЯ, М., 2009 (С АНАЛИЗОМ ПРЕДШЕСТВУЮЩЕЙ ЛИТЕРАТУРЫ, С. 205-210); Л.И. ЛИФШИЦ, «ИЗОБРАЖЕНИЯ ЦАРСТВЕННОГО ОТРОКА В ТИМПАНАХ ФАСАДОВ ДМИТРИЕВСКОГО СОБОРА ВО ВЛАДИМИРЕ», ЛАЗАРЕВСКИЕ ЧТЕНИЯ 2011. ИСКУССТВО ВИЗАНТИИ, ДРЕВНЕЙ РУСИ, ЗАПАДНОЙ ЕВРОПЫ, М., 2012, С. 184-201.

5. СКУЛЬПТУРНАЯ ДЕКОРАЦИЯ СОХРАНИЛАСЬ В ФРАГМЕНТАХ ОТ СОБОРА РОЖДЕСТВА БОГОРОДИЦЫ В БОГОЛЮБОВЕ. 1158 Г. (ВОРОНИН, 1961-1962, Т. 1, с. 201-261; ВАГНЕР, 1969, с. 66-95) И ПЕРВОГО УСПЕНСКОГО СОБОРА ВО ВЛАДИМИРЕ, 1160 Г. (ВОРОНИН, 1961-1962, Т. 1, с. 149-186, 354-375; ВАГНЕР, 1969, с. 95-121, 207-220), А ТАКЖЕ В ХОРОШО 
СОХРАНИВШИХСЯ СКУЛЬПТУРНЫХ ПРОГРАММАХ ЦЕРКВИ ПОКРОВА НА НЕРЛИ, 1166 Г. (ВОРОНИН, 1961-1962 Г. Т. 1, с. 262-301; ВАГНЕР, 1969, с. 125-191) И ДМИТРИЕВСКОГО СОБОРА ВО ВЛАДИМИРЕ, 1193-1197 ГГ. (ВОРОНИН, 1961-1962, Т. 1. с. 396-437; ВАГНЕР, 1969, с. 231-415). ОТ ХІІІ В. ДО НАС ДОШЛИ СКУЛЬПТУРНЫЕ ФРАГМЕНТЫ СОБОРА РОЖДЕСТВА БОГОРОДИЦЫ В СУЗДАЛЕ, 1222 Г. (ВОРОНИН, 1961-1962, Т. 2, С. 19-42; Г.К. ВАГНЕР, БЕЛОКАМЕННАЯ РЕЗЬБА ДРЕВНЕГО СУЗДАЛЯ: РОЖДЕСТВЕНСКИЙ СОБОР. ХІІІ ВЕК М., 1975) И ДЕКОРАЦИИ ГЕОРГИЕВСКОГО СОБОРА В ЮРЬЕВЕ-ПОЛЬСКОМ (ВОРОНИН, 1961-1962, Т. 2, С. 68-107; Г.К. ВАГНЕР, МАСТЕРА ДРЕВНЕРУССКОЙ СКУЛЬПТУРЫ: РЕЛЬЕФЫ ЮРЬЕВАПОЛЬСКОГО, М., 1966). ВАЖНАЯ ПОПЫТКА ОБОЩЕНИЯ - ДИССЕРТАЦИЯ, ОПУБЛИКОВАННАЯ В ВИДЕ КНИГИ: М.С. ГЛАДКАЯ, РЕЛЬЕФЫ ДМИТРИЕВСКОГО СОБОРА, М., 2009.

6. СМ. В. ДОБРОХОТОВ, ПАМЯТНИКИ ДРЕВНОСТЕЙ ВО ВЛАДИМИРЕ КЛЯЗЕМСКОМ, М., 1848, c. 140-141; Halle, 1929, s. 60-62; D. Ainalov, Geschichte der russischen Monumentalkunst der vormoskowitischen Zeit, Berlin, 1932, s. 78-82; В.Н. ЛАЗАРЕВ, СКУЛЬПТУРА ВЛАДИМИРОсузДАЛЬСКОЙ РУсИ, ИРИ, М., 1953, т. 1, с. 404, 414, 416.

7. ПОИСК НЕКАНОНИЧЕСКИХ ИСТОЧНИКОВ ОТКРЫЛ Н.П. КОНДАКОВ, КОТОРЫЙ НАХОДИЛ ОБЪЯСНЕНИЕ СИМВОЛИКЕ В «ГОЛУБИНОЙ КНИГЕ». СМ.: И. ТОЛСТОЙ, Н. КОНДАКОВ, РУССКИЕ ДРЕВНОСТИ В ПАМЯТНИКАХ ИСКУССТВА, СПБ., 1899, ВЫП. 6, С. 26-58, 36. В КРАЙНЕЙ ФОРМЕ ЭТОТ ПОДХОД ВОПЛОТИЛСЯ В СЛЕДУЮЩЕМ ВЫСКАЗЫВАНИИ: «СТЕНЫ ЭТИХ ХРАМОВ ПРЕДСТАВЛЯЮТ СОБОЙ ПРЕТВОРЕННЫЕ В КАМНЕ ЯЗЫЧЕСКИЕ НАРОДНЫЕ ВЕРОВАНИЯ, СВОЕГО РОДА ПЛАСТИЧЕСКИЙ ФОЛЬКЛОР» (А.Г. РОММ, РУССКИЕ МОНУМЕНТАЛЬНЫЕ РЕЛЬЕФЫ, М., 1953, С. 12).

8. А.Н. ГРАБАР СЧИТАЛ, ЧТО ВО ВЛАДИМИРО-СУЗДАЛЬСКОЙ СКУЛЬПТУРЕ СОЕДИНИЛИСЬ «ТРАДИЦИИ УЧЕНОГО ИСКУССТВА» СО «СТИХИЕЙ НАРОДНОГО ТВОРЧЕСТВА», И ОТМЕЧАЛ, ЧТО «ФИГУРА ДАВИДА, ВЛЕКУЩАЯ ЗА СОБОЙ ИНТЕРПРЕТАЦИЮ ВСЕЙ СКУЛЬПТУРНОЙ КОМПОЗИЦИИ КАК ИЛЛЮСТРАЦИИ К ПСАЛМАМ, БЫЛА ИСКУССТВЕННО ПРИСТАВЛЕНА К ЗНАКОМЫМ ВАМ ПО БОЛЕЕ РАННИМ ПАМЯТНИКАМ СВЕТСКОМУ ЦИКЛУУ. СМ.: А.И. ГРАБАР, «СВЕТСКОЕ ИЗОБРАЗИТЕЛЬНОЕ ИСКУССТВО ДОМОНГОЛЬСКОЙ РУСИ И “СЛОВО О ПОЛКУ ИГОРЕВЕ”», ТРУДЫ ОТДЕЛА ДРЕВНЕРУССКОЙ ЛИТЕРАТУРЫ, Л., 1962, Т. 18, С. 254-263, 258, 261.

9. воРОНИН, 1961-1962, т. 1, с. 268-269, 432, 435, 437.

10. В.П. ДАРКЕВИЧ, «ОБРАЗ ЦАРЯ ДАВИДА ВО ВЛАДИМИРО-СУЗДАЛЬСКОЙ СКУЛЬПТУРЕ», КРАТКИЕ СООБЩЕНИЯ ИНСТИТУТА АРХЕОЛОГИИ, ВЫП. 99 (1964), С. 46-53 (ДАЛЕЕ - ДАРКЕВИЧ, 1964).

11. ВАГНЕР, 1969, с. 114, 195, 320; Г.К. ВАГНЕР, Г.Ф. ВЛАДЫШЕВСКАЯ, ИСКУССТВО ДРЕВНЕЙ РУСИ, М., 1993, С. 90.

12. ВАГНЕР, 1969, С. 44. МЫ НЕ РАССМАТРИВАЕМ ЗДЕСЬ ТЕОРИИ, ПОЯВИВШИЕСЯ ПОСЛЕ ВЫХОДА НАШЕЙ СТАТЬИ В 1996 Г., ТАК ИЛИ ИНАЧЕ ПОВЛИЯВШЕЙ НА ИССЛЕДОВАТЕЛЕЙ.

13. ИСТОРИКО-ФИЛОЛОГИЧЕСКИЙ КОММЕНТАРИЙ ДАННОГО ФРАГМЕНТА ТЕКСТА ИЕЗЕКИИЛЯ И ЕГО СРАВНЕНИЕ С ОПИСАНИЕМ ХРАМА СОЛОМОНА СМ.: W. Zimmerli, Ezekiel, 2: A Commentary on the Book of the Prophet Ezekiel, Chapters 25-48, Philadelphia, 1983, p. 382-388. Word Biblical Commentary, vol. 29: Ezekiel, 20-48 / By L.C. Allen, Dallas, 1990, p. 212-236. ИНТЕРЕСНА СРЕДНЕВЕКОВАЯ ТРАДИЦИЯ ИСТОЛКОВАНИЯ ЭТОГО ОПИСАНИЯ XРАМА. ГРЕЧЕСКИЙ КОММЕНТАРИЙ ФЕОДОРИТА КИРСКОГО (V В.) ПРОСТО ПЕРЕСКАЗЫВАЕТ ТЕКСТ ИЕЗЕКИИЛЯ (PG. T.81. Col. 1225-1226). В ЛАТИНСКОЙ ТРАДИЦИИ ОСНОВОПОЛАГАЮЩЕЕ ЗНАЧЕНИЕ ИМЕЛ КОММЕНТАРИЙ СВ. ИЕРОНИМА (IV-V ВВ.): Corpus Christianorum, Series Latina, vol. 75, Turnholt, 1964, p. 599-602. 
14. ЦИТИРУЕТСЯ СВ. ЛЕОНТИЙ НЕАПОЛЬСКИЙ: ИОАНН ДАМАСКИН. ТРИ ЗАЩИТИТЕЛЬНЫЕ СЛОВА ПРОТИВ ПОРИЦАЮЩИХ СВЯТЫЕ ИКОНЫ ИЛИ ИЗОБРАЖЕНИЯ (ПЕР. А. БРОНЗОВА), СПБ., 1893, С. 137. ЭТО СВИДЕТЕЛЬСТВО «ЛЕОНТИЯ, ЕПИСКОПА НЕАПОЛЯ КИПРСКОГО, ИЗ ПЯТОЙ КНИГИ ОБ АПОЛОГИИ ХРИСТИАН ПРОТИВ ИУДЕЕВ И О СВЯТЫХ ИКОНАХ» БЫЛО ПРОЧИТАНО И НА VII ВСЕЛЕНСКОМ СОБОРЕ (787 Г.): ДЕЯНИЯ ВСЕЛЕНСКИХ СОБОРОВ, ИЗДАННЫЕ В РУССКОМ ПЕРЕВОДЕ ПРИ КАЗАНСКОЙ ДУХОВНОЙ АКАДЕМИИ, КАЗАНЬ, 1891, Т. 7, С. 130.

15. ИДЕЯ, ВЫСКАЗАННАЯ М.В. АЛПАТОВЫМ, БЫЛА ОСТОРОЖНО ПОДДЕРЖАНА В.Н. ЛАЗАРЕВЫМ И ТАК ВОШЛА В АКАДЕМИЧЕСКУЮ «ИСТОРИЮ РУССКОГО ИСКУССТВА»: ИРИ, Т. 1, С. 399-100.

16. ВОРОНИН, 1961-1962, т. 1, с. 319, 268-269.

17. ВАГНЕР, 1969, с. 140, 142.

18. АНАЛОГИИ МОЖНО НАЙТИ КАК В ВИЗАНТИЙСКОЙ, ТАК И В РОМАНСКОЙ ИКОНОГРАФИИ. МНОГОЧИСЛЕННЫЕ ОБРАЗЫ АНГЕЛОВ В РОСПИСЯХ СОФИИ КИЕВСКОЙ ПОЗВОЛЯЮТ УВИДЕТЬ ВСЕ КОНКРЕТНЫЕ ПАРАЛЛЕЛИ.

19. БЛИЖАЙШАЯ АНАЛОГИЯ - ЛИКИ В МЕДАЛЬОНАХ В ЦЕНТРЕ ИЗОБРАЖЕНИЙ ШЕСТИКРЫЛЫХ АНГЕЛОВ, СОХРАНИВШИХСЯ В СКУЛЬПТУРНОЙ ДЕКОРАЦИИ ЮЖНОЙ СТЕНЫ ГЕОРГИЕВСКОГО СОБОРА В ЮРЬЕВЕ ПОЛЬСКОМ.

20. ВАГНЕР, 1969, С. 88-94.

21. La Gerusalemme celeste: Immagini della Gerusalemme celeste dal III al XIV secolo, Milano, 1983, p. 148-149 (ДАЛЕЕ La Gerusalemme celeste, 1983); В. Kuhnel, From the Earthly to the Heavenly Jerusalem: Representations of the Holy City in Christian Art of the First Millenium, Rome - Freiburg - Wien, 1987, p. 145-149 (ДАЛЕЕ - Kuhnel, 1987).

22. Г.К. ВАГНЕР, БЕЛОКАМЕННАЯ РЕЗЬБА ДРЕВНЕГО СУЗДАЛЯ, ИЛ. 46-51, С. 66-70.

23. ВАГНЕР, 1969 , С. 140-143.

24. La Gerusalemme celeste. 1983, p. 151; El «Beato» de Saint-Sever ms. lat. 8878 de la Bibliothèque nationale de Paris, Madrid. 1984.

25. ХАРАКТЕРНЫЕ ПРИМЕРЫ ПРИВЕДЕНЫ В КАТАЛОГЕ: La Gerusalemme celeste, 1983, p. 150-156.

26. ИЗОБРАЖЕНИЯ НА ФАСАДЕ, РАСПОЛОЖЕННЫЕ ВЫШЕ АРКАТУРНО-КОЛОНЧАТОГО ПОЯСА, МОГУТ ВОСПРИНИМАТЬСЯ КАК НАХОДЯЩИЕСЯ ВНУТРИ ГРАДА.

27. О СИМВоЛИКЕ ЧИСЛА 7 СМ.: D. Forstner, Die Welt der christlichen Symbole, Innsbruck, 1966; V.F. Hopper, Mediaeval Number Symbolism, New York, 1938.

28. МОНОГРАФИЧЕСКОЕ ИССЛЕДОВАНИЕ ТАКИХ КАДИЛЬНИЦ С ПОДРОБНЫМ КАТАЛОГОМ СОХРАНИВШИХСЯ ПАМЯТНИКОВ СМ.: М.т. Gousset, "Un aspect du symbolisme des encensoirs romans: La Jerusalem Céleste”, Cah. Arch., 1982, vol. 30, p. 81-106.

29. C.R. Dodwell, The Various Arts: De Diversis Artibus, Oxford: Clarendon Press, 1961 (reprint 1986); J.G. Hawthorne, C. Stanley Smith, On divers arts: The Treatise of Theophilus, Chicago, 1963; МАНУСКРИПТ ТЕОФИЛА «ЗАПИСКА О РАЗНЫХ ИСКУССТВАХ», СООБЩЕНИЯ ВЦНИЛКР, 1963, ВЫП. 7, с. 148-153 (ДАЛЕЕ - МАНУСКРИПТ ТЕОФИЛА, 1963).

30. ТАМ ЖЕ, С. 148-149.

31. СМ.: МАНУСКРИПТ ТЕОФИЛА, 1963, с. 149. 
32. ХАРАКТЕРНО ОБИЛИЕ ЗООМОРФНОЙ СИМВОЛИКИ, ИЗОБРАЖЕНИЙ ЛЬВОВ, ГРИФОНОВ, ПТИЦ, СОЧЕТАЮЩИХСЯ С ПАЛЬМОВИДНЫМИ ОРНАМЕНТАМИ. ВСТРЕЧАЮТСЯ И ОТДЕЛЬНЫЕ МИФОЛОГИЧЕСКИЕ МОТИВЫ, К ПРИМЕРУ, КЕНТАВРЫ. ЯРКИЙ ОБРАЗЕЦ ТАКОГО ДЕКОРА ДАЕТ СДЕЛАННЫЙ В ВИДЕ ГОРОДА-ХРАМА СЕРЕБРЯНЫЙ СОСУД КОНЦА ХІІ В. ИЗ СОКРОВИЩНИЦЫ САН-МАРКО В ВЕНЕЦИИ. СМ.: I. Kalavrezou, "Incense Burner in the Shape of a Domed Building" in H. Evans and W. Wixom, eds., The Glory of Byzantium: Art and Culture of the Middle Byzantine Era (843-1261), New York, 1997, no 176, p. 250-251; M. Da Villa Urbani, "Perfume brazier in the form of a domed building," Byzantium 330-1453 (London, 2008), no 176, p. 423; Architecture as Icon. Perception and Representation of Architecture in Byzantine Art, Princeton, 2010, $\mathrm{n}^{\circ}$ 2, p. 160-161.

33. ВАГНЕР, 1969, С. 160-162; ДАРКЕВИЧ, 1964, С. 46-53. ДОЛГОЕ ВРЕМЯ РЯД ИССЛЕДОВАТЕЛЕЙ ПОЛАГАЛ, ЧТО, В ОТЛИЧИЕ ОТ ЦЕРКВИ ПОКРОВА НА НЕРЛИ ГДЕ ИЗОБРАЖЕНИЯ СОПРОВОЖДАЮТ НАДПИСИ С ИМЕНЕМ ДАВИДА, В ДМИТРИЕВСКОМ СОБОРЕ БЫЛ ПРЕДСТАВЛЕН ЦАРЬ СОЛОМОН (Н.П. КОНДАКОВ, Г.К. ВАГНЕР И ДР.). ОДНАКО И ТАМ БЫЛА ОБНАРУЖЕНА НАДПИСЬ, ПОЗВОЛИВШАЯ С УВЕРЕННОСТЬЮ ИДЕНТИФИЦИРОВАТЬ ОБРАЗ ТРОННОГО ЦАРЯ КАК ДАВИДА. СМ.: Г.К. ВАГНЕР, «ОБ ОТКРЫТИИ РЕЗНЫХ ЗАПИСЕЙ СРЕДИ ФАСАДНОЙ СКУЛЬПТУРЫ ДМИТРИЕВСКОГО СОБОРА ВО ВЛАДИМИРЕ», СОВЕТСКАЯ АРХЕОЛОГИЯ, 1976, № 1, С. 270-272.

34. М.В. ЩЕПКИНА, МИНИАТЮРЫ ХЛУДОВСКОЙ ПСАЛТЫРИ, М., 1977, Л. 1 ОБ.

35. См.: Е.т. De Wald, et al., eds., The Illustrations in the Manuscripts of the Septuagint, vol. 3: Psalms and Odes, p. 2: Vaticanus Graecus 752, Princeton, 1942.

36. ЛЕНТА, СКОРЕЕ ВСЕГО, ИМИТИРУЕТ ИМПЕРАТОРСКИЙ ЛОР, НО ПРИ ЭТОМ НАПОМИНАЕТ И ЛЕНТУ, ОПОЯСЫВАЮЩУЮ СИНДОН АРХИЕРЕЯ В ОБРЯДЕ ОСВЯЩЕНИЯ ХРАМА. ОБ ЭТИХ ОДЕЯНИЯХ СМ.: А.М. ЛИДОВ, «ОБРАЗ “ХРИСТА-АРХИЕРЕЯ” В ИКОНОГРАФИЧЕСКОЙ ПРОГРАММЕ СОФИИ ОХРИДСКОЙ», ВИЗАНТИЯ И РУСЬ, М., 1989, С. 66-68. ВОЗМОЖНОСТЬ ТАКОЙ ИНТЕРПРЕТАЦИИ ОБРАЗА И ОДЕЯНИЙ НАХОДИТ ПОДДЕРЖКУ В СВЯТООТЕЧЕСКОЙ ТРАДИЦИИ, В КОТОРОЙ ПОДЧЕРКИВАЕТСЯ МЫСЛЬ ОБ АРХИЕРЕЙСКОМ ДОСТОИНСТВЕ ДАВИДА: «КАК БУДТО ОБЛЕЧЕННЫЙ ЕПИСКОПСТВОМ... САМ ОН БЫЛ И ЖЕРТВОЙ, И ЖРЕЦОМ, И ЖЕРТВЕННИКОМ» (ИОАНН ЗЛАТОУСТ, БЕСЕДЫ НА КНИГУ БЫТИЯ, М., 1993, Т. 2, C. 846).

37. О СИМВОЛИКЕ И ИКОНОГРАФИИ ОБРАЗА СМ.: Н. Steger, David Rex et Propheta: Konig David als vorbildliche Verkorperung des Herrschers und Dichters im Mittelalter, nach Bilderstellungen des achten bis zwolften Jahrhunderts, Nurnberg, 1961.

38. О ТЕОФАНИЧЕСКИХ ОБРАЗАХ ХРИСТА СМ.: Ihm Chr. Belting, "Theophanic Images of Divine Majesty in Early Medieval Italian Church Decoration," in W. Tronzo, ed., Italian Church Decoration of the Middle Ages and Renaissance, Bologne, 1989, p. 43-59; Y. Christe, Les grands portails romans: Études sur l'iconologie des théophanies romanes, Genève, 1969.

39. Th. Von Bogyay, "Hetimasia", Reallexikon für byzantischen Kunst (RBK), 1971, Bd. 2, Col 1189-1202.

40. ВАГНЕР, 1969 , С. 356

41. ИХ ОБРАЗЫ ТРАДИЦИОННО ВКЛЮЧАЮТСЯ В ИКОНОГРАФИЮ ТЕОФАНИИ: Ј. Lafontaine Dosogne, “Theophanies -visions auxquelles participent les prophètes dans Lart byzantin après la restauration des images", in A. Grabar, éd., Synthronon: Art et Archéologie de la fin de L'Antiquité et du Moyen Âge, Р., 1968, Р. 135-143. НЕДАВНО Л.И. ЛИФШИЦ ПРЕДЛОЖИЛ СЧИТАТЬ ФИГУРЫ ПО СТОРОНАМ ОТ ЭТИМАСИИ ИЗОБРАЖЕНИЯМИ ЕВАНГЕЛИСТОВ, 
ОДНАКО НАМ ПО-ПРЕЖНЕМУ ВЕРСИЯ ОБ ОБРАЗАХ ПРОРОКОВ ПРЕДСТАВЛЯЕТСЯ БОЛЕЕ ВЕРОЯТНОЙ: Л.И. ЛИФШИЦ, «ИЗОБРАЖЕНИЯ ЦАРСТВЕННОГО ОТРОКА В ТИМПАНАХ ФАСАДОВ ДМИТРИЕВСКОГО СОБОРА ВО ВЛАДИМИРЕ», ЛАЗАРЕВСКИЕ ЧТЕНИЯ 2011. ИСКУССТВО ВИЗАНТИИ, ДРЕВНЕЙ РУСИ, ЗАПАДНОЙ ЕВРОПЫ, М., 2012, С. 189.

42. ЗНАМЕНАТЕЛЬНО, ЧТО ТЕМА ТЕОФАНИИ БЫЛА КЛЮЧЕВОЙ И В СКУЛЬПТУРНОЙ ДЕКОРАЦИИ РОМАНСКИХ ПОРТАЛОВ ХІІ В. В НОВЕЙШЕЙ ЛИТЕРАТУРЕ РАЗЛИЧАЮТ НЕСКОЛЬКО СИМВОЛИЧЕСКИХ ВЕРСИЙ ЭТОЙ ТЕМЫ: P.к. Klein, "Programmes eschatologiques, fonction et réception historiques des portails du XII s.", Cahiers de civilisation médiévale, 1990, vol. 33, p. 317-349.

43. СЛОВАРЬ БИБЛЕЙСКОГО БОГОСЛОВИЯ, ПОД РЕД. К. ЛЕОН-ДЮФУРА, БРЮССЕЛЬ, 1974, c. 253-256, 413-419.

44. А.М. ЛИДОВ, «ОБРАЗ НЕБЕСНОГО ИЕРУСАЛИМА В ВОСТОЧНО-ХРИСТИАНСКОЙ ИКОНОГРАФИИ» in А. БАТАЛОВ, А. ЛИДОВ, РЕД.-СОСТ., ИЕРУСАЛИМ В РУССКОЙ КУЛЬТУРЕ, М., 1994, С. 17-19, ИЛ. 3.

45. Kuehnel, 1987, p. 164-165, fig. 125.

46. Ю.А. ЛИМОНОВ, ВЛАДИМИРО-СУЗДАЛЬСКАЯ РУСЬ: ОЧЕРКИ СОЦИАЛЬНО-ПОЛИТИЧЕСКОЙ ИСТОРИИ, Л., 1987, с. 48-64.

47. ДАРКЕВИЧ, 1964, С. 46-53.

48. СМ.: ВОРОНИН, 1961-1962, т. 1.

49. ПОЛНОЕ СОБРАНИЕ РУССКИХ ЛЕТОПИСЕЙ (ПСРЛ), СПБ., 1908, Т. 2, С. 581; ПАМЯТНИКИ ЛИТЕРАТУРЫ ДРЕВНЕЙ РУСИ (ПЛДР): ХІІ ВЕК, М., 1980, С. 324-325.

50. ХАРАКТЕРНО, ЧТО В ХРИСТИАНСКОЙ ИКОНОГРАФИИ ОНИ ЧАСТО ИЗОБРАЖАЮТСЯ ВМЕСТЕ, КАК, НАПРИМЕР, В КОМПОЗИЦИИ «СОШЕСТВИЯ ВО АД».

51. ПлДР: ХІІ ВЕК, С 24-325.

52. воРонин, 1961-1962, т. 1, с. 201.

53. РЕЗИДЕНЦИЯ В ААХЕНЕ СТАЛА НА СРЕДНЕВЕКОВОМ ЗАПАДЕ АРХИТЕКТУРНЫМ И СИМВОЛИЧЕСКИМ ОБРАЗЦОМ. СМ.: К.Ј Conant, Caroligian and Romanesque Architecture: 8001200, London - New York, 1990, p. 46-51; E. Kleinbauer, “Charlemagne's Palace Chapel at Aachen and Its Copies", Gesta, 1965, vol. 4, p. 2-11.

54. В.Н. ТАТИЩЕВ, ИСТОРИЯ РОССИЙСКАЯ С САМЫХ ДРЕВНЕЙШИХ ВРЕМЕН, М., 1768, КН. 1, С. 293, 500; КН. 3, С. 127, 487. СМ. ТАКЖЕ: ВОРОНИН, 1961-1962, Т. 1, С. 330-331. ОБ УЧАСТИИ РОМАНСКИХ МАСТЕРОВ ВО ВЛАДИМИРСКОМ СТРОИТЕЛЬСТВЕ СМ. ВАЖНЫЙ ОЧЕРК НА ОСНОВЕ СОВРЕМЕННЫХ АРХИТЕКТУРНО-АРХЕОЛОГИЧЕСКИХ ИССЛЕДОВАНИЙ: О. ИОАННИСЯН, «ЛОМБАРДСКИЕ ЗОДЧИЕ НА РУСИ: “РУССКАЯ РОМАНИКА" ХІІ ВЕКА», ПИНАКОТЕКА, Т. 16-17, 2003/1-2, С. 10-19

55. ОБ ЭТОМ СМ. В СТАТЬЯХ Н.Н. ВОРОНИНА: «СКАЗАНИЕ О ПОБЕДЕ НАД БОЛГАРАМИ 1164 Г. И ПРАЗДНИКЕ СПАСА», ПРОБЛЕМЫ ОБЩЕСТВЕННО-ПОЛИТИЧЕСКОЙ ИСТОРИИ РОССИИ И СЛАВЯНСКИХ СТРАН, М., 1963, С. 88-91; «ЖИТИЕ ЛЕОНТИЯ РОСТОВСКОГО И ВИЗАНТИЙСКОРУССКИЕ ОТНОШЕНИЯ ВТОРОЙ ПОЛОВИНЫ ХІІ В., ВИЗАНТИЙСКИЙ ВРЕМЕННИК, 1963, Т. 23, С. 23-46; «ИЗ ИСТОРИИ РУССКО-ВИЗАНТИЙСКОЙ ЦЕРКОВНОЙ БОРЬБЫ ХІІ В.», ВИЗАНТИЙСКИЙ ВРЕМЕННИК, 1965, Т. 26, С. 190-218. СМ. ТАКЖЕ: Ю.А. ЛИМОНОВ, «ЛЕТОПИСЕЦ АНДРЕЯ БОГОЛЮБСКОГО», КУЛЬТУРА ДРЕВНЕЙ РУСИ, М., 1906, С. 113-117. 
56. СМ.: Н.Н. ВОРОНИН, «АНДРЕЙ БОГОЛЮБСКИЙ И ЛУКА ХРИЗОВЕРГ» ВИЗАНТИЙСКИЙ ВРЕМЕННИК, 1962, Т. 21, С. 29-50.

57. НАДО ОТМЕТИТЬ, ЧТО В ЭТИХ ОБРАЗАХ НЕ БЫЛО НИЧЕГО ПРИНЦИПИАЛЬНО ЧУЖДОГО ПРАВОСЛАВНОЙ ВЕРЕ, ХОТЯ В ЦЕЛОМ ОНИ БЫЛИ СОВЕРШЕННО НЕ ТРАДИЦИОННЫ.

58. НЕ ИСКЛЮЧЕНО, ЧТО ЧАСТЬЮ ЭТОГО ИЛИ ДРУГОГО ДАРА ИМПЕРАТОРА БЫЛИ ПРОИСХОДЯЩИЕ ИЗ ВЛАДИМИРА РОМАНСКИЕ ЭМАЛЕВЫЕ БРАСЛЕТЫ (armillae), СОСТАВЛЯЮЩИЕ ЧАСТЬ ПАРАДНЫХ ОДЕЯНИЙ. СМ.: В.П. ДАРКЕВИЧ, «РОМАНСКАЯ ЦЕРКОВНАЯ УТВАРЬ ИЗ СЕВЕРО-ВОСТОЧНОЙ РУСИ», КУЛЬТУРА ДРЕВНЕЙ РУСИ, М., 1966, c. 65-68; P.E. Sehramm, Herrschaftszeichen und Staatssymbolik, Stuttgart, 1955, s. 547 (АВTOР СВЯЗАЛ БРАСЛЕТЫ С АНДРЕЕМ БОГОЛЮБСКИМ); H. Swarzenski, Monuments of Romanesque Art, London, 1967, p. 181. PI. 181; Die Zeit der Staufer: Katalog der Ausstellung, Stuttgart, 1977, Bd 1, № 541, s. 402-404; Bd. 2. Аbb. 331-332 (ПО стИЛю АВТОР ДАТИРУЕТ БРАСЛЕТЫ $1175-1180$ гг.).

59. ПАНИКАДИЛО БЫЛО ПОДАРЕНО ИМПЕРАТОРОМ ОКОЛО 1166 Г. В СВЯЗИ С КАНОНИЗАЦИЕЙ КАРЛА ВЕЛИКОГО: Р. Lasko, Ars Sacra: 800-1200, London, 1972, p. 216, pl. 246.

60. ПлДР: ХІІ ВЕК, С. 326-327.

61. P.B. Jurgenson, "Romanische Einflusse in der altrussischen Goldschmiedeplastik", Zeitschrift fur bildende Kunst. 1928-1929, Bd. 10, S. 236-252; В.П. ДАРКЕВИЧ, ПРОИЗВЕДЕНИЯ ЗАПАДНОГО ХУДОЖЕСТВЕННОГО РЕМЕСЛА В ВОСТОЧНОЙ ЕВРОПЕ Х-ХV ВВ., М., 1967, С. 23-25; И.А.СТЕРЛИГОВА, «ИЕРУСАЛИМЫ КАК ЛИТУРГИЧЕСКИЕ СОСУДЫ В ДРЕВНЕЙ РУСИ», ИЕРУСАЛИМ В РУССКОЙ КУЛЬТУРЕ, С. 52-55.

62. ПЛДР: ХІІ ВЕК, С. 326-327.

63. ВОРОНИН, 1961-1962, т. 1, с. 185.

64. А.М. ВЫСОЦКИЙ, «ХРАМ ИЕЗЕКИИЛЯ КАК ИСТОЧНИК НАРУЖНОГО СКУЛЬПТУРНОГО ДЕКОРА ВЛАДИМИРО-СУЗДАЛЬСКИХ ХРАМОВ ХІІ-ХІІІ ВВ. Sic et Non», ДРЕВНЕРУССКОЕ ИСКУССТВО. РУСЬ И СТРАНЫ ВИЗАНТИЙСКОГО МИРА. ХІІ ВЕК, СПБ., 2002, С. 255-269. ПРИМЕЧАТЕЛЬНО, ЧТО БОЛЬШАЯ СТАТЬЯ ПОСВЯЩЕНА РАЗБОРУ ДВУХ ДОКЛАДОВ С ОПУБЛИКОВАННЫМИ КО ВРЕМЕНИ НАПИСАНИЯ СТАТЬИ КОРОТКИМИ ТЕЗИСАМИ.

65. СМ. ВЫШЕ ПРИМ. 14

66. РИШАР СЕН-ВИКТОРСКИЙ АКЦЕНТИРУЕТ МЫСЛЬ, ЧТО ИЗОБРАЖЕНИЯ БЫЛИ КАК ВНУТРИ, ТАК И СНАРУЖИ ХРАМА: Richardi S. Victoris, «In Visionem Ezechielis", PL, T. 196, Col. 588-589; Andreae de Sancto Victore, “Opera," T. 6: Expositionem in Ezechielem, M.A. Singer, ed., Turnholt, 1991, p.171. В РАБОТЕ С ЛАТИНСКИМИ ТЕКСТАМИ Я ПОЛЬЗОВАЛСЯ ЦЕННЫМИ КОНСУЛЬТАЦИЯМИ НЫНЕ ПОКОЙНОГО М.Л. ГАСПАРОВА, ЗА ЧТО ПРИНОШУ ЕМУ ГЛУБОКУЮ ПРИЗНАТЕЛЬНОСТЬ.

67. ПОСЛЕДУЮЩИЕ ЛАТИНСКИЕ АВТОРЫ НЕ ДОБАВИЛИ ПРАКТИЧЕСКИ НИЧЕГО НОВОГО К КОММЕНТАРИЮ ИЕРОНИМА. О ЗНАЧЕНИИ КНИГИ ИЕЗЕКИИЛЯ В ЛАТИНСКОЙ ТРАДИЦИИ См.: W. Neuss, Das Buch Ezechiel in Theologie und Kunst bis zum Ende des XII. Jahrhunderts, Munster, 1912.

68. Biblia Latina cum glossa ordinaria. Facsimile Reprint of the Editio Princeps Adolph Rusch of Stassburg 1480/81. Brepols; Turnholt, 1992, vol. 3, p. 304.

69. W. Cahn, “Architecture and Exegesis: Richard of St.-Victor's Ezekiel Commentary and Its Illustrations," Art Bulletin, LXXV, 1994, p. 53-68 
70. J. Gardelles, «Recherches sur les origines des façades à étages d'arcatures des églises médiévales», Bulletin monumental, CXXXVI, 1978, p. 113-133.

71. СМ. ПРИМ. 35.

72. A. Iacobini, Visioni dipinti: Immagini della contemplazione negli affrechi di Bawit, Roma, 2000.

\section{RÉSUMÉS}

$\mathrm{Au}$ milieu $\mathrm{du} \mathrm{XII}^{\mathrm{e}}$ siècle, sous le règne du prince Andrej Bogoljubskij, un type architectural inhabituel d'église russe est apparu dans Vladimir, la nouvelle capitale. Il combinait la structure en croix grecque inscrite avec la décoration romane. Selon certaines sources écrites, les premières églises de ce type furent construites par des maîtres de l'Occident latin envoyés au prince Andrej par Frédéric Barberousse. Les décorations sculpturales de ces églises témoignent d'un concept symbolique composite. Cet article soumet l'hypothèse selon laquelle l'iconographie des sculptures de Vladimir et de Suzdal symbolise la Jérusalem céleste. La vision d'Ezéchiel (Ez. 41:17-19), faisant état d'un décor sculptural du Temple céleste en serait la source écrite la plus probable. Cette vision explique l'apparence du décor sculpté sur les façades des églises, alliant les images des chérubins, des palmiers, des lions et des humains. On y trouve aussi la clé des principaux thèmes iconographiques, parmi lesquels les énigmatiques «masques" pourraient être des représentations des chérubins sur toute la muraille du pourtour du Temple céleste. La ceinture d'arcades centrales des façades avaient certainement pour objet d'évoquer le mur de Jérusalem. La représentation du roi David sur son trône, thème principal des trois façades, peut être interprétée dans ce même contexte de Jérusalem. On peut observer de très proches analogies dans l'iconographie romane, notamment dans la décoration des encensoirs représentant la Jérusalem céleste. Dans ce contexte, les « jérusalem d'or » liturgiques, qui avaient probablement fait partie du cadeau de Frédéric Barberousse au prince Andrej, avaient pu être utilisés comme une sorte de modèle pour les nouvelles églises russes et leurs extraordinaires décorations sculpturales.

A vision of city and temple: Jerusalem symbolism in sculptural icons on facades of twelfthcentury Russian churches

In the mid-twelfth century, under the reign of Prince Andrei Bogoliubskii, an unusual architectural type of Russian church appeared in the new capital of Vladimir. It combined the Byzantine cross-in-square structure with Romanesque decoration. According to some written sources, the first churches of this type were built by masters from the Latin West who had been sent to prince Andrei by Frederick Barbarossa. The sculptural decoration of these churches demonstrates a shared symbolic concept. This paper hypothesizes that the iconography of Vladimir-Suzdalian carvings symbolizes the Heavenly Jerusalem. The most likely literary source for it is the vision of Ezekiel (Ez. 41:17-19) describing the sculptural decoration of the Heavenly Temple. Ezekiel's vision sheds light on the combination of cherubs, palm trees, lions and humans of the carved decoration on the church facades. The same text gives a key for understanding the principal iconographic themes. Among them, the enigmatic "masks," which could be the depictions of cherubs by all the wall round about in the Heavenly Temple. The arcades in the middle of the facades probably meant to invoke the image of the walls of Jerusalem. The 
repetition on the three facades of the major theme, the image of King David enthroned, could be interpreted along the same lines. The closest analogy one may find in Romanesque iconography is the decoration of censers depicting the Heavenly Jerusalem. In this context, the liturgical "golden jerusalems," which probably were part of Frederick Barbarossa's gift to Prince Andrei, could have been used as models for the new Russian churches and their extraordinary sculptural icons.

\section{AUTEUR}

\section{АЛЕКСЕЙ М. ЛИДОВ}

Université Lomonosov, Moscou 